\title{
Mirroring and Mentalizing in Autism - Detection of Different Types of Movements and Emotions in Autism Spectrum Disorder
}

\author{
Cologne, August 2018 \\ Thesis submitted for \\ The Degree of B.Sc. in Psychology \\ University of Cologne, Germany \\ Summer Semester 2018 \\ By \\ Milena Marx \\ Matriculation Number: 6048625 \\ Advisor: Alexander Geiger \\ Supervisor I: Prof. Dr. Dr. Kai Vogeley \\ Supervisor II: Prof. Dr. Jan Peters
}




\section{Abstract}

Two different neural systems and their associated functions have been identified by social neuroscience as important factors of social interaction: the mirror neuron system (MNS) and the mentalizing system (MENT), mirroring and mentalizing, respectively. Since anomalies in social behavior are core to autism spectrum disorder, observation of impairments in this disease is particularly interesting for research on those functions. Yet, the majority of studies concentrated respectively on one of the two networks or associated abilities or did not take into account clinical populations to learn more about the synergy of both during social encounters. This study is the first to examine those complex skills between two diagnostic groups using an appropriate behavioral approach. A new set of stimuli allowed to compare mirroring and mentalizing by addressing both recognition abilities with the same visual input, controlling for potentially confounding variables.

Results indicate anomalies in the detection of mood, but not in the detection of actions in autism, suggesting impairments in mentalizing but normal functioning of mirroring abilities. Since no differences between mirroring and mentalizing in the group of healthy control participants were detected, findings can be interpreted as an indication for a primal separation of both functions or neural networks, respectively. However, a synergy seems to be probable, but needs to be clarified by further research. Additionally, a significantly higher number of unanswered trials was observed in persons with autism, indicating a tendency of avoidance of uncertainty in autism. 


\section{Abbreviations}

$\begin{array}{ll}\text { ASD } & \text { Autism spectrum disorder } \\ \text { ADHS } & \text { Attention deficit hyperactivity disorder } \\ \text { AQ } & \text { Autism-Spectrum Quotient } \\ \text { EQ } & \text { Empathy Quotient } \\ \text { fMRT } & \text { Functional magnetic resonance imaging } \\ \text { HC } & \text { Healthy controls } \\ \text { HFA } & \text { High functioning autism } \\ \text { ICD-10 } & \text { International Statistical Classification of Diseases and Related Health } \\ & \text { Problems } \\ \text { M } & \text { Mean } \\ \text { MENT } & \text { Mentalizing system } \\ \text { MNS } & \text { Mirroring system } \\ \text { SD } & \text { Stand deviation }\end{array}$




\section{Table of Contents}

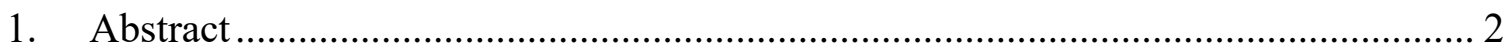

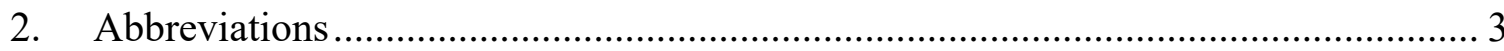

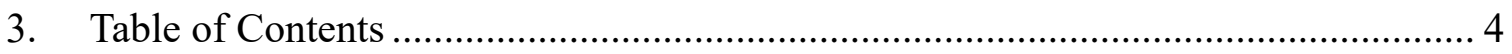

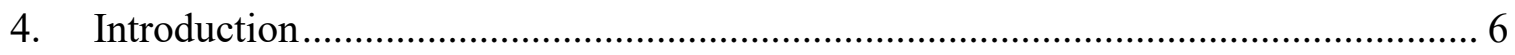

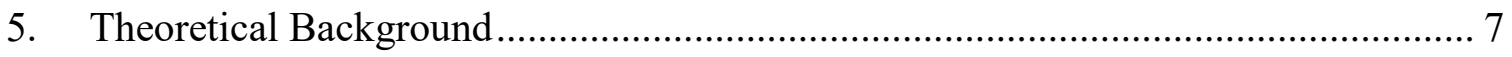

5.1. Social Cognition and nonverbal behavior ................................................. 8

5.2. Mirroring and Mentalizing and their neural correlates ................................ 9

5.2.1. The Mirror Neuron System .............................................................. 9

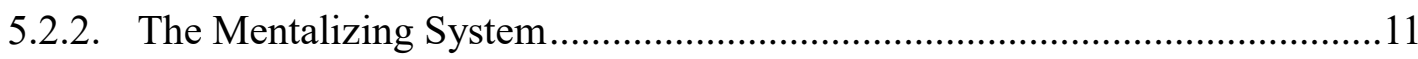

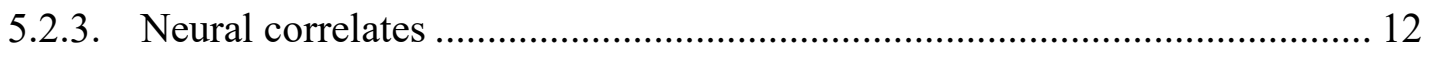

5.2.4. The Synergy of Mirror Neuron System and Mentalizing System ............... 12

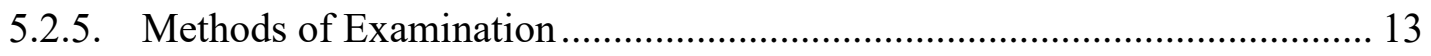

5.3. Autism Spectrum Disorder ................................................................ 14

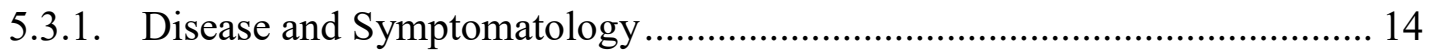

5.3.2. Possible causes of the disease and explanatory approaches........................ 15

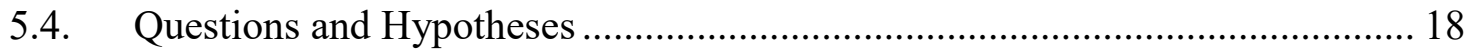

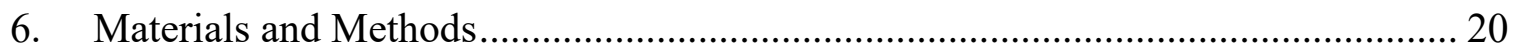

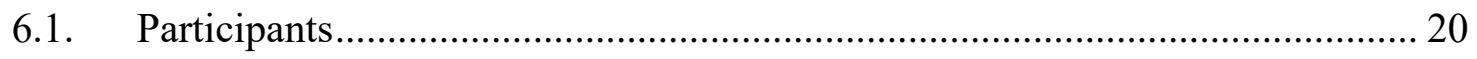

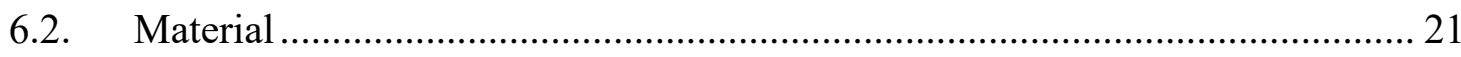

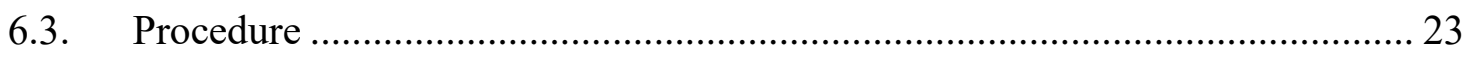

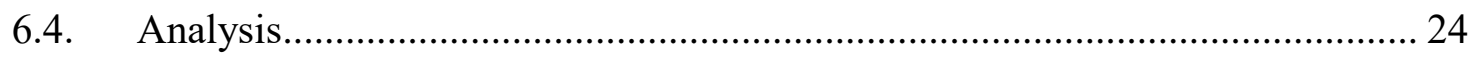

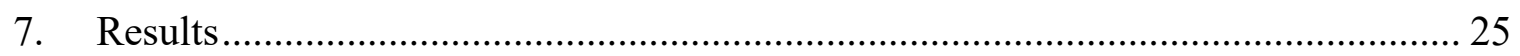

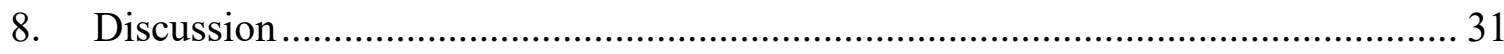




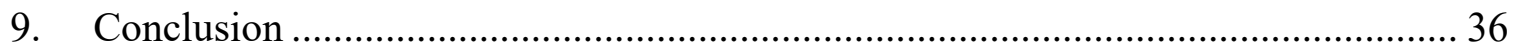

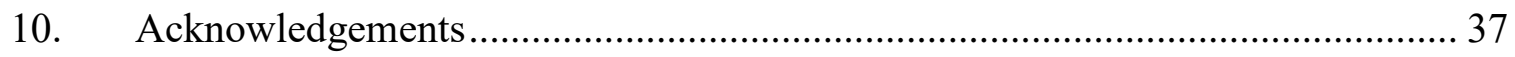

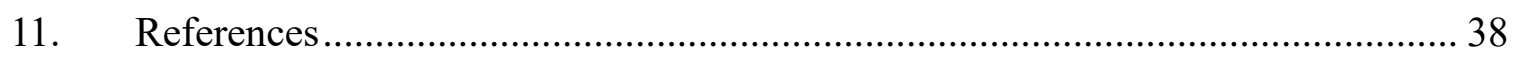

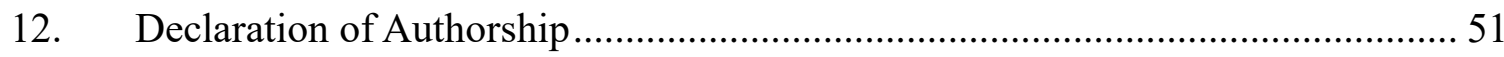

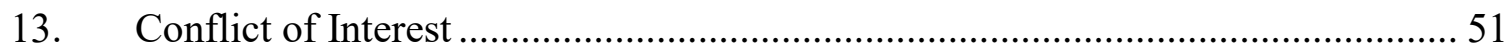




\section{Introduction}

A train ride seems like the most everyday thing. Early in the morning we take our seat opposite to a tired looking person. The yawning of the traveler is contagious, and while we try to suppress it we think to ourselves: "Well, I can feel you." Without the use of language, we are able to put ourselves in the position of others. Doing so we can understand their state of mind, their mood and we can comprehend the intentions and meanings of their actions. It all appears to be trivial and perfectly normal. However, as humans we possess unique abilities to interact with other individuals which makes us the social species that we are (Tomasello, Carpenter, Call, Behne, \& Moll, 2005). As such, competences like non-verbal communication (Knapp \& Daly, 2011), gaze behavior (Brooks \& Meltzoff, 2015) or imitation (Marshall \& Meltzoff, 2014a) are essential for the understanding of others, learning processes and for navigating through complex social situations. Several psychological disorders are affected by anomalies in those social mechanisms (Timmermans \& Schilbach, 2014) what leads to various difficulties in everyday life. In autism spectrum disorder (ASD) deficits in understanding other minds are particularly striking (BaronCohen, 2000) and therefore a central component of the diagnosis (American Psychiatric Association \& American Psychiatric Association, 2013). To process and understand other persons behavior, first the action or the movement needs to be recognized - "What is the person doing?". Subsequently, the view behind the movement allows to detect how this action is performed - "How is the person doing?" (Thioux, Gazzola, \& Keysers, 2008). Interestingly the recognition of movements ("What?") seems to be less difficult for persons with autism compared to the detection of mood (“How?”) (Hamilton, Brindley, \& Frith, 2007).

Little is known about the specific functionalities, commonalities and differentiations between those features, which are also referred to as mirroring (action processing and imitating) and mentalizing (understanding of emotions, beliefs and intentions). Until now both recognition mechanisms were not examined convincingly. They were addressed with substantially dissimilar stimuli which results in inconclusive comparisons. Thus, no conclusions could be drawn about the connections and the differences between the recognition of moods and the recognition of movements from previous studies. Consequently, although the clinical picture of ASD is suitable for examining these abilities in detail, appropriate studies in this field are lacking, that could refine the knowledge about the disease and possible treatments. In the current study, both detection abilities could be examined using the same visual input, i.e. better controllable. Recently developed 
stimuli allowed deeper insight in these abilities and their synergy in both persons with autism and control participants (healthy controls $=\mathrm{HC}$ ) by raising comparable data of action and mood recognition rates for the first time. Hence, better than ever before, these two abilities could now be compared and differentiated, as the study's objective was. Obtained results could lead to a more differentiated picture of autism and thus to a better understanding of the disease. They might indicate that indeed, not every part of social interaction in autism is impaired, but that only special, subtle parts of human encounter lead to difficulties. The study contributes to ongoing research around social impairments in autism and could lead to insights that could help affected persons and their relatives, possibly by an adapted treatment. New insights about important brain mechanisms and their synergy could also be valuable for research about other diseases and the general understanding of the human social brain. The present work thus is to examine differences between mood and action recognition skills both in persons with autism and HC, to reveal if emotion and movement detection is impaired equally in autism and to gain knowledge about the synergy of both abilities.

\section{Theoretical Background}

In order to understand the distinction between mirroring and mentalizing abilities, the clinical picture of autism and the current state of research, the following is to lay out the theoretical background of this work. A brief introduction to nonverbal behavior and communication is presented first. Since one of the study's objectives was differentiate between action and mood detection, which correlate to mirroring and mentalizing skills, those abilities will be characterized subsequently. Current literature on this topic and references to neuropsychological relations will be presented. Since the understanding of others is impaired in autism, the observation of mirroring and mentalizing in affected persons is particularly interesting. The clinical picture of ASD will be described with a focus on occurring anomalies in social interaction. Pathophysiological and neuropsychological theories about possible causes of the disease and explanatory approaches will be introduced. 


\subsection{Social Cognition and nonverbal behavior}

As human beings, we always seem to manage effortlessly in social situations. We communicate verbally and non-verbally with our fellow human beings, sometimes openly, sometimes very subtly. Those cognitive processes occurring in social interactions are referred to as social cognition. Nonverbal cues occupy a special position in research about social cognition. Usually nonverbal information, meaning actions distinct from speech, can be processed very quickly and intuitively (Kuzmanovic, Schilbach, Lehnhardt, Bente, \& Vogeley, 2011). According to Mehrabian (2017) nonverbal behavior includes facial expressions, hand and arm gestures, postures, positions, and various movements of the body or the legs and feet. Clearly, encoding and decoding of nonverbal cues are of high importance in every human encounter and play a large role in social life (Boyatzis \& Satyaprasad, 1994; Knapp \& Daly, 2011; Segrin, 2000; Vogeley \& Bente, 2010). In human ontological development nonverbal behaviors are the first kind of communication (Knapp \& Daly, 2011; Tomasello et al., 2005). Beginning in earliest childhood, prior to language, imitation can be observed in infants, indicating observation-execution linkages, so-called neural mirroring mechanisms (Marshall \& Meltzoff, 2014b). Actions of others are perceived and accordingly reproduced into own actions, they seem to be "mirrored" by the child without the need of any verbal instruction. Also, gaze following plays an important part in nonverbal interaction early in life, since it is indispensable for joint attention, the shared focus of two agents on an object. Shared attention episodes, creating a triadic social interaction, are considered to be necessary for many aspects of infant development and learning, including language acquisition (Moore, Dunham, \& Dunham, 2014). According to Baron-Cohen (2000), children later develop a so-called theory of mind, which enables them to put themselves in the position of other persons. This enables to understand other agent's intentions, beliefs and emotions. It is therefore also referred to as mentalizing or "mindreading" (C. D. Frith \& Frith, 2006).

Nonverbal cues are encoded and decoded through a multitude of processes in the brain. When talking about those brain mechanisms in social encounters, mostly the term 'human social brain' is used (Mars et al., 2012). Until now safe conclusions about those processes cannot be drawn. Current studies thus focus on the two key mechanisms of perceiving and processing nonverbal information: the previously mentioned abilities for (a) mirroring and (b) mentalizing. The term mirroring refers to the ability to recognize an action by matching it to one's own representations of that movement in memory (Gallese, Keysers, \& Rizzolatti, 2004). The 
connection between perceiving and reproducing an action hence includes both the ability to recognize a motion and the ability to imitate this same movement. The current study merely observes the recognition part of this feature, since no imitation task is required to answer the questions of interest. Action detection abilities nevertheless will be referred to as mirroring due to simplicity and comparability to the term mentalizing. Utilizing these terms will allow an easier comprehension of the topic and later interpretations of results. In parallel, the term mentalizing indicates the capability to understand other person's mental states, wishes or beliefs, like seeing "behind the curtain" of the perceived action to understand the goal and intention (Fishman, Keown, Lincoln, Pineda, \& Müller, 2014). Both features are involved in social encounters and often are difficult to discriminate, since social situations are full of diverse nonverbal cues in any case. Up to now, both functions of interest could not be examined with controlled stimuli, demarcated from one another. The design of the study at hand however allows to observe both skills of understanding nonverbal cues in a differentiated manner for the first time.

\subsection{Mirroring and Mentalizing and their neural correlates}

The two features are almost exclusively mentioned in connection with the associated brain networks: (a) the so-called mirror neuron (MNS) and (b) the so-called mentalizing system (MENT), which is also known as the theory of mind network (Premack \& Woodruff, 1978). Both key networks, of which the undelaying neural mechanisms remained largely undetermined, have become an integral part of social neuroscience research (Fishman et al., 2014). Theories on both constructs are supported by an increasing number of studies, investigating their neural correlates. Not only on the behavioral, but also on the neurological level the mechanisms of associated social abilities can be observed (Hasson \& Frith, 2016). What remains unanswered is the question about the interaction of both networks. Experiments mostly focused on the single constructs respectively. Only in more recent studies both were investigated at the same time (de Lange, Spronk, Willems, Toni, \& Bekkering, 2008), however, stimuli differed significantly between the networks they were addressing.

\subsubsection{The Mirror Neuron System}

A mirror neuron is a neuron that shows the same activity pattern both when an ape or a human being watches or executes a movement. The term mirror neuron system (MNS) indicates a 
group of those neurons that is active when observing the actions and behavior of others (Gallese et al., 2004). The first descriptions of mirror neurons in macaques by the team of Giacomo Rizzolatti in 1996 (Rizzolatti, Fadiga, Gallese, \& Fogassi, 1996) had a tremendous influence on social neuroscience research. For the first time a network of neurons was found that was activated when motor actions were either executed or observed in other individuals, what appeared as a "mirroring" of other's behavior. It was thus suggested, that these neurons had both a motor and a visual property, providing the physiological mechanism for perception-action coupling (Buccino et al., 2008; Gangopadhyay \& Schilbach, 2012). The discovery was quickly followed by neurological studies on humans, watching and performing human specific actions in human environments (Cochin, Barthelemy, Roux, \& Martineau, 1999; Hari et al., 1998). In 2010 the first direct examination of mirror neurons in humans was presented (Mukamel, Ekstrom, Kaplan, Iacoboni, \& Fried, 2010).

A diversity of tasks is proposed to be performed by the MNS and speculation about the significance and characteristics of the network continue as it remains object of ongoing research. Proposed possible functions include the imitation and understanding of movements (Iacoboni, 2009; Rizzolatti, Fogassi, \& Gallese, 2001) and the understanding of other's actions and intentions by simulating (Fogassi et al., 2005; Gallese \& Goldman, 1998). Others state that the MNS could be crucial for social behavior and might be jointly responsible as the neuronal basis for the human capacity of empathy and self-awareness (Iacoboni \& Dapretto, 2006; Pfeifer, Iacoboni, Mazziotta, \& Dapretto, 2008). Also, language acquisition is discussed as a MNS-task (Arbib, 2005; Häberling, Corballis, \& Corballis, 2016; Rizzolatti \& Arbib, 1998). The importance of the ability of mirroring and the MNS for learning new skills by observing and imitating, but also for social learning is beyond question, although specific functions in demarcation to other networks and assigned brain regions remain subject of ongoing discussions.

Because of their invasive nature, single-cell recordings to detect characteristic properties of mirror neurons in humans are only rarely possible. Due to ethical implications, a recording of cellular activity through an intracranial implantation of depth electrodes is not possible, but if patients, e.g. with pharmaceutical intractable epilepsy, agree to an examination, as it offers a chance for a surgical treatment. Direct evidence for mirror neurons, like presented by Mukamel et al. (2010) is therefore exceptional. Most research on the MNS has consequently been conducted on monkeys. Theories of the human MNS were repeatedly criticized and controversially discussed 
(Hickok, 2009; Pascolo \& Budai, 2014). Critics argue that experimental techniques, such as fMRT measures, are limited and that the exact function of the MNS remain uncertain. Contradicting the main stream in research, Csibra (2008) suggested that the recognition and interpretation of an action rather precedes mirroring than following it and thus is anticipatory. By now, a great number of experiments, applying a variety of techniques were carried out, supporting the existence of a human MNS (Ferrari \& Rizzolatti, 2014). Without doubt, the evidence for this neral network is constantly increasing, stating that it is activated when humans observe an action as well as when they execute the same. Whilst the network might still not be understood completely, findings still contradict critics who have expressed doubts about the existence of mirror neurons altogether. However, mirroring cannot be considered sufficient for the ability to interpret and understand emotions and intentions in others and in one-self. Evidence for its involvement in empathy must be questioned (Baird, Scheffer, \& Wilson, 2011). At this point another important network for the social brain, the mentalizing system, is to be introduced.

\subsubsection{The Mentalizing System}

Mentalizing indicates the ability to interpret other person's behavior by ascribing them mental states or inferring contents of their mind, including beliefs and intentions (Fishman et al., 2014; Fonagy, Gergely, Jurist, \& Target, 2004). The so-called Mentalizing System (MENT) or Theory of Mind Network consists of all brain areas relevant and activated during this task. Mirroring skills are not suitable to explain every part of social interaction, the ability to put oneself in the position of another person or to understand their inner states and moods, as it was believed in earlier research on the MNS (Gallese et al., 2004; Pfeifer et al., 2008). The ability to mentalize however seems to play a major role in reading the mental states of others and to take over their perspective (C. D. Frith \& Frith, 2006). Mentalizing thus is thought to be related to functions previously attributed to mirroring and to be as important for social cognition (Hooker, Verosky, Germine, Knight, \& D'Esposito, 2008). As research continued, evidence accumulated that the MNS is responsible for the understanding of others by observance. The theory of mind network instead holds the ability to empathize with someone or making inferences about the mental states of other agents (C. D. Frith \& Frith, 2006). 


\subsubsection{Neural correlates}

Results of a number experiments, mainly functional magnetic resonance imaging (fMRT) studies, are predominantly consistent in detecting underlying brain regions for both MNS and MENT. Regions of the MNS, thus areas that are recruited both by execution and observation of actions, are mostly allocated to regions along the premotor cortex (PMC), the anterior intraparietal sulcus (aIPS), the inferior frontal gyrus (IFG) and the inferior parietal lobule (IPL) (Becchio et al., 2012; Van Overwalle \& Baetens, 2009). According to several authors MENT includes the (anterior) medial prefrontal cortex (mPFC), the temporoparietal junction (TPJ), the posterior temporal sulcus, and the temporal poles (C. D. Frith \& Frith, 2006; Saxe \& Powell, 2006; Vogeley, 2017). Most results thus revealed that action understanding and mentalizing recruit different brain areas (see figure 1). It can therefore be assumed, that mirroring and mentalizing are separate psychological and neural mechanisms. The exact interplay is yet to be investigated.
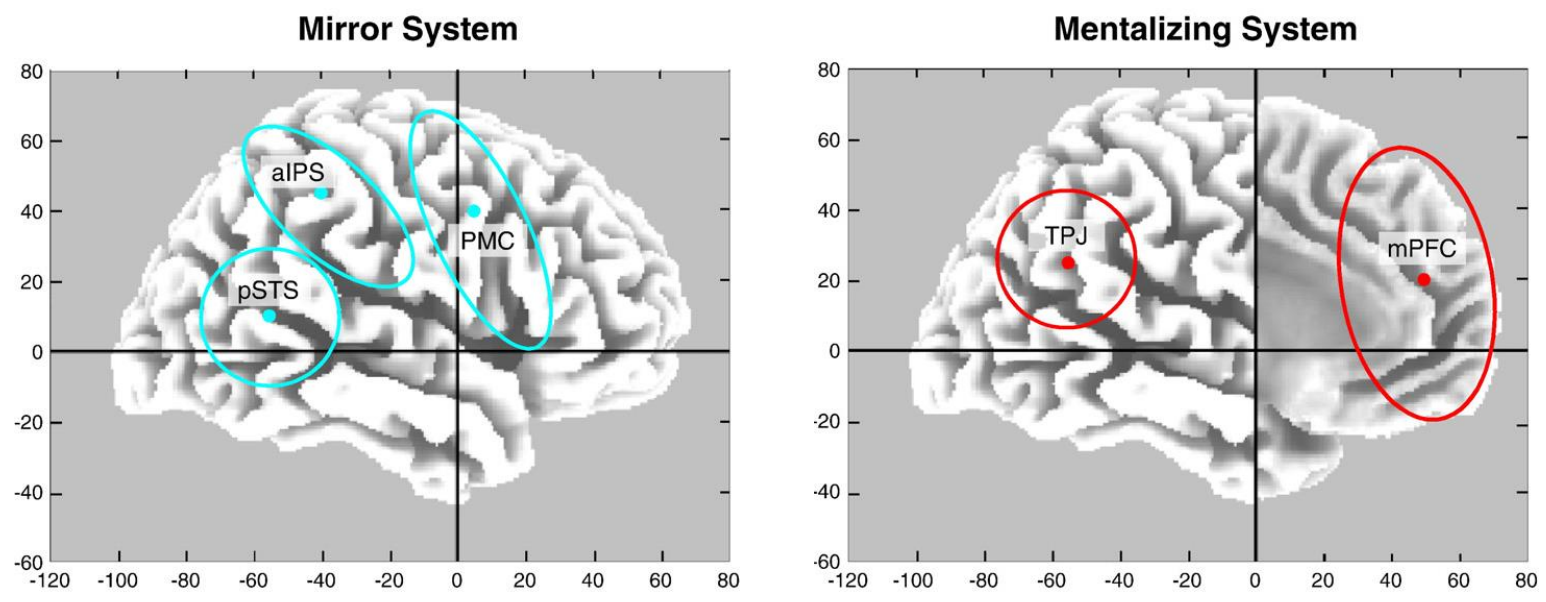

Figure 1. The regions of interest involved in the mirror and mentalizing system placed in an $\mathrm{x}-\mathrm{y}-\mathrm{z}$ Talairach atlas. Their centers are indicated by a dot. (from Van Overwalle \& Baetens, 2009)

\subsubsection{The Synergy of Mirror Neuron System and Mentalizing System}

Up until now the exact and distinguished functions of the MNS and MENT, as well as their interplay could not be defined with certainty. Findings and opinions on characteristics, specific functional areas and conjunctions of those networks differ. (Little is known about how these two hypothetical systems cooperate and inform each other.) Discussions about the question, which of the two systems describes social interaction best have now given way to the idea, that the systems 
complement each other. Only recently Vogeley (2017) suggested, that the MNS serves the early detection of signals, whilst the MENT serves as a social evaluation system in a later stage of information processing. Based on recent findings in neuroscience, he assumes that, concerning social encounters, the MNS is related to movements in space and bodily signals in order to scan for socially salient information. By contrast, the MENT is directed to the inner state of a person, including oneself to evaluate socially salient information (Vogeley, 2017).

\subsubsection{Methods of Examination}

To understand previous findings about MNS and MENT and critics concerning the results, it is important to discuss used methods and study designs. The two functions that are of interest in the study at hand were mostly examined separately in previous investigations. Studies concentrated respectively on one of the two networks of interest, thus isolating them artificially Utilized stimuli mostly were substantially different for the separate networks. Studies dealing with MENT or mentalizing skills included verbal stories, moving shapes and interactive games (C. D. Frith \& Frith, 2006). MNS or mirroring abilities, such as imitation skills, usually were addressed by tasks including the observation and the execution of movements (Iacoboni \& Dapretto, 2006; Iacoboni et al., 1999; Van Overwalle \& Baetens, 2009). Only few authors took into account MNS and MENT to the same extent, finding that mirroring and mentalizing serve different, but complementary functions in social interaction (de Lange et al., 2008). However, in those experiments, mirroring or mentalizing mechanisms or rather MNS and MENT were stimulated differently. Especially the visual input used to address those two features mostly differed greatly. For example, de Lange et al. (2008) used pictures of persons performing usual or unusual actions on an object with usual or unusual means. The static pictures thus showed very different movements and mostly were burdened with possibly confounding features like gender, ethnicity or attractivity of the person in the picture. For the majority of published studies, it is therefore not certain if truly the intended manipulation lead to the observed differences or if other input information was the reason for these results. Until now there has not been any kind of stimulus set to test the networks in the same vein without the possible interference of other unknown variables

(e.g. sex, age, ethnicity). Only by ensuring that nothing but the directed attention on either the action or the mental state of another person affects the neural activity, new conclusions about those systems and underlying skills can be drawn. There has been no behavioral study to show 
differences between the performances on mirroring and mentalizing skills yet. Only very recently Lammers and Geiger produced a set of stimuli that is equally applicable to investigate MNS and MENT. The study at hand thus is the first to appropriately investigate both abilities in one behavioral experiment with convincing stimuli, comparing a clinical population with HC. Not only will it allow to draw more conclusions about differences between two important functions of the social brain. It also considers the comparison of a control population and a group of persons with autism. This disease, known for discrepancies in precisely these brain areas of interest, will be introduced now.

\subsection{Autism Spectrum Disorder}

Those previously described skills of mirroring and mentalizing support humans tremendously in navigating through all sorts of complex social situations. Autism spectrum disorder (ASD) is a neurodevelopmental disorder lacking this ability. Thus, it is highly interesting to observe the performances of affected individuals to further differentiate both functions and their actual influence on the symptomatology. This could help to better understand the disease with its associated problems in everyday social life and the two social abilities, including associated neural networks.

\subsubsection{Disease and Symptomatology}

According to the International Classification of Diseases (ICD-10-CM, 2018, 2017), autism is a profound developmental disorder, characterized by anomalies in social interaction, communication and by restricted and repetitive behavior. The term High Functioning Autism (HFA) thereby indicates a higher level of cognitive functions (with an IQ of 70 or greater). Since individuals with this specific diagnose (F84.4 in ICD-10) show normal cognitive functioning, they only differ in autism specific traits compared to a general population. Investigating social skills, nonverbal behavior or communication in HFA is consequently highly interesting to gain new insights about the human social brain and associated functions and abilities. Studies quoted here including autistic individuals were also mainly carried out with HFA patients.

Findings on prevalence of ASD vary. Fombonne (2009) found rates for autism between 0.9 and $1.1 \%$ in a systematic review. Very consistently a preponderance of male patients is found. A ratio of 2-3: 1 in favor of the male gender is realistic (Idring et al., 2012). The disease of autism 
shows a heterogenous disorder pattern regarding etiology and phenotype. Although heterogeneous symptoms can be manifested, it is best characterized by an impairment of social cognition, including dysfunction in social interaction and communication as well as limited, repetitive behavioral patterns, interests and activities (Deutsche Gesellschaft für Kinder- und Jugendpsychiatrie, Psychosomatik und Psychotherapie (DGKJP), 2016). Disturbances in reciprocal social interaction concern initiation, maintenance and structuring of interpersonal relationships. Dysfunctions in communication are apparent in language development and particularly in nonverbal communication like facial expression, gestures and gaze behavior. Symptoms occur in earliest childhood and persist lifelong. Over the lifespan the disease challenges affected persons in various ways.

\subsubsection{Possible causes of the disease and explanatory approaches}

Until today no single cause or a bundle of causes that lead to autistic disorders could be named. Increasing evidence proposes that autism is a complex disorder that can only be explained by diverse deficits that co-occur (F. Happé, Ronald, \& Plomin, 2006). Trying to identify causes of typical symptoms of ASD led to several explanatory models. To be able to put the study at hand into context and to understand its importance for ongoing research, some of those models will be briefly introduced now. To get an overview of the different models, these will be divided into pathophysiological and neuropsychological causes.

Pathophysiology: Well documented causes are genetic and early environmental risk factors, especially concerning pregnancy (Persico \& Napolioni, 2013). Genetic causes for autism have proven to be extremely diverse and highly complex (Persico \& Napolioni, 2013). Reliable biological markers, e.g. to facilitate the diagnosis, could not be identified up to now. Biologically induced disturbances of brain functions, e.g. dysfunction in the central perception apparatus, are suspected to partly cause typical autistic symptomatology (U. Frith, Morton, \& Leslie, 1991; Kaiser \& Pelphrey, 2012). It is thus especially the field of social neuroscience that has been of great interest in research on ASD. Precise neural mechanisms underlying the social impairments could not be detected yet. However, studies, conducted with fMRT revealed dysfunctions in several brain areas, including frontal cortex areas, the temporal lobe including the superior temporal sulcus (Redcay, 2008), basal temporal areas (Castelli, Frith, Happé, \& Frith, 2002), the amygdala and the fusiform face area (Schultz, 2005). 
Neuropsychological linkages between brain structures and behaviors: To comprehend typical autistic behaviors, three prominent neuropsychological theories have mostly been discussed as explanatory models in the past. In most cases, people with ASD experience difficulties in more than one of these three areas, which are illustrated in the following.

Executive functions: Consistent findings indicate impairments in the domain of executive functions in ASD (Kenworthy, Black, Harrison, Rosa, \& Wallace, 2009; Pennington \& Ozonoff, 1996). These enable an individual to plan actions step by step, logically and with foresight, to implement them consistently and to take changed circumstances into account during actions. There are reports about anomalies in action planning, the maintenance of solution strategies to achieve goals, difficulties in divergent thinking and sequencing, irritability and relapse into rigid schemata (Bishop \& Norbury, 2005).) Also, cognitive and conscious attention control are part of these functions. Impairments in these abilities or atypical activation pattern in the brain are suggested to lead to decreased processing performances and attention difficulties in autism (Bertone, Mottron, Jelenic, \& Faubert, 2003).

Central coherence: Central coherence is the ability to integrate individual elements of perception into an overall context and to summarize them as a realistic and consistent picture. Attractions and information are correctly linked, recorded and stored as an overall picture (Happé, 1997). Persons with autism have great difficulty in gathering and processing information, i.e. interpreting sensory stimuli and impressions in context, as a whole (Happé, 1996). Probably environmental information is processed differently, namely preferably in detail and not in the overall context (Happé \& Frith, 2006). The result is an unconnected juxtaposition of details, which can explain weaknesses and strengths in autism. Possibly stereotypical movements and preoccupation with always the same objects could be explained by this theory of weak central coherence. Also detailed knowledge and savant skills could result from this feature. Yet, some authors do not support these suggestions, due to missing observable links between repetitive behavior and measures of central coherence (South, Ozonoff, \& Mcmahon, 2007).

Theory of mind: According to Baron-Cohen (2001), ToM describes the ability to assume of consciousness in other people and to recognize them in oneself, i.e. to assume feelings, needs, ideas, intentions, expectations and opinions in others. In persons with autism this ability is impaired (Baron-Cohen, Leslie, \& Frith, 1985; Baron-Cohen, Wheelwright, Hill, Raste, \& Plumb, 
2001). Mostly they lack cognitive functions that enable to mentally put oneself in another person's position. Mentalizing and forming a theory of the mental in oneself and others thus is not possible. Hypotheses about anomalies in theory of mind functions can be transferred to a lack in mentalizing skills in autism. A connection between presented anomalies in behavior and disruptions in the MENT in autism thus can be drawn thanks to ongoing research (Fishman et al., 2014; Spengler, Bird, \& Brass, 2010; White, Frith, Rellecke, Al-Noor, \& Gilbert, 2014). For some time, causes for atypical behaviors in autism were also assumed in the MNS. The "broken-mirrorhypothesis" (Ramachandran \& Oberman, 2006; Williams, Whiten, Suddendorf, \& Perrett, 2001) bridged the gap between the recently discovered mirror neurons and autism. The theory expressed the idea that a dysfunction of the MNS could be responsible for the social-cognitive difficulties of persons with ASD. Whilst some authors argued for this idea (Iacoboni \& Dapretto, 2006; Oberman et al., 2005), evidence against it accumulated (Dinstein, Thomas, Behrmann, \& Heeger, 2008; Hamilton, 2008). ) Dinstein et al. (2010) claimed that imitation or detection of hand movements in autism could be slower than in $\mathrm{HC}$ which could lead to mistakes during the scanning of the brain and hence to a misinterpretation towards a decrease in MNS activity. Also, a 2013 meta-analysis found little support for the hypothesis. Data were more compatible with the assumption that the descending (top-down) modulation of social reactions in autism was atypical (Hamilton, 2013). Taking these findings together, it can be assumed that there is no anomaly in mirroring skills, including the recognition of movements, or the MNS in autism. However, there seem to be differences between persons with autism and healthy individuals in mentalizing abilities or the MENT. This assumption suggests that persons with autism have less problems in recognizing actions than in recognizing emotions of others. other differences could explain less MNS activity in autism.

In conclusion, two different neural systems and their associated functions have been identified by social neuroscience as important factors of social interaction: the MNS and the MENT, mirroring and mentalizing, respectively. Evidence raises, that both systems or skills play an eminent role for the processing of social information and the mutual understanding of intentions, seemingly largely independent from each other. Additionally, closer examinations of both systems in autism remain interesting to better understand characteristic difficulties in social behavior. Yet, the majority of studies concentrated respectively on one of those two networks or did not take into account clinical populations to learn more about the synergy during social encounters. Questions 
about the synergy of mirroring and mentalizing thus remained unanswered for the greatest part. Studies, trying to include both networks or their connection in persons with autism did not do so by comparing associated behavioral skills, but by comparing resting-state fMRT images (Fishman et al., 2014). An appropriate approach to compare those complex skills between two diagnostic groups was missing, until a new set of stimuli, created in the work group in which also this study was conducted, now opened the door to this exciting field of research. Although most recent experiments in this research field included fMRT examinations, it is now possible to compare mirroring and mentalizing without imaging techniques, but with behavioral studies, as it will be presented here. Unlike most previous investigations that used substantially different stimuli to address the separate networks (de Lange et al., 2008), equal stimuli can now be used for the research of both abilities. With those, recognition skills for movements and emotions can finally be investigated properly. Consequently, this experiment is put forward to compare detections rates for actions and mood in persons with autism and controls.

\subsection{Questions and Hypotheses}

According to presented literature, two separate functions of the human social brain are distinctively important for social interaction, (a) mirroring and (b) mentalizing. Since those abilities have usually been examined separately, no experiment is known in which both were addressed with the same visual input. With recently produced video sequences, mirroring and mentalizing performance finally could be compared without any possibly confounding variables. Those stimuli allowed to compare the performance on tasks addressing those functions between controls and clinical populations. Especially in ASD anomalies in social behavior can be observed which particularly interesting for research in social cognition. For the study at hand, following concrete questions resulted:

(1) Is there a difference in performance between mirroring and mentalizing, conjecturing that both are addressed with the same input?

(2) To what extent do people with autism and healthy controls differ in mirroring and mentalizing performance?

Considering background information, theoretical deductions include the presumption that no differences between recognition rates for movements and emotions among controls will occur. 
Persons with autism however are expected to perform better in mirroring than in mentalizing tasks. The following hypotheses result:

(1) Hypothesis 1: Persons with autism perform significantly better in behavioral tasks addressing mirroring abilities compared to tasks addressing mentalizing abilities.

(2) Hypothesis 2: In the group of HCs, there are no significant differences between mirroring and mentalizing performances.

Comparing the two diagnostic groups, the following hypotheses emerge:

(3) Hypothesis 3: Recognition rates for persons with autism are significantly decreased in mentalizing tasks compared to $\mathrm{HC}$.

(4) Hypothesis 4: Recognition rates for persons with autism are as high in mirroring tasks as they are in $\mathrm{HC}$.

Furthermore, it is suspected, that scores for autistic traits, measured with the Autismus Quotient AQ (Baron-Cohen, Wheelwright, Skinner, Martin, \& Clubley, 2001), correspond to the performance in mentalizing in autism. No correlation is assumed between those scores and the performance in mirroring, since only the recognition of emotions is presumably impaired in the group of patients. Empathy plays a decisive role in social interaction and a connection between empathy and mirroring (Pfeifer et al. 2008), or between empathy and mentalizing skills (Hooker et al. 2008) is being assumed. An instrument for measuring this ability, the Empathy Quotient EQ (Baron-Cohen \& Wheelwright, 2004) was included to this study to investigate a possible relation between the score on the scale and the performance in mirroring and mentalizing. The resulting hypotheses are:

(5) Hypothesis 5: A negative correlation between the score achieved on the AQ and the performance in mentalizing is visible in the group of persons with autism.

(6) Hypothesis 6: There is a positive correlation between the score achieved on the EQ and the performance in mirroring or mentalizing.

In the following the testing of those previously presented hypotheses, including sample, material and methods is to be explained. 


\section{Materials and Methods}

To test the hypotheses presented in chapter 5.4., the experiment was conducted with two different populations, first with a group of controls, and second with a group of persons diagnosed with ASD. Results of this event-related study, consisting of two conditions, were compared between the groups. A new, homogenous stimulus set was created and utilized to measure the detection rates for actions and moods with as few likely confounding variables as possible. Sample and material, including two questionnaires, will be explained more accurately hereinafter. The operationalization of the target figures mirroring and mentalizing will be explained. Finally, the procedure, data processing and statistical analysis will be described.

\subsection{Participants}

For this behavioral study participants for the control group were recruited via mailing lists and word of mouth. All participants in the autism group had been diagnosed with HFA at the autism outpatient clinic for autism in adulthood at the university clinic of Cologne and were recruited via mailing lists. Comorbid neurological and psychiatric diseases, current psychotropic medication or acute suicidality served as exclusion criteria for both groups. Participants had to be between 18 and 60 years old and to possess a normal or corrected visual acuity. All participants were naïve to the purpose of the experiment. Before the start of the experiment all participants gave written and oral informed consent in accordance with the ethics committee of the University of Cologne and the declaration of Helsinki (World Medical Association, 2013).

The final sample included 25 volunteers with autism ( 9 females, mean age $=41.32, S D=$ 9.85 ) and 28 control subjects ( 15 females, mean age $=34.54, S D=10.94)$. More sample details are displayed in table 1. 
Table 1

Participants demographic and questionnaire data

\begin{tabular}{|c|c|c|c|c|c|c|c|c|c|}
\hline \multirow[t]{2}{*}{ Variables } & \multicolumn{3}{|c|}{ Controls } & \multicolumn{3}{|c|}{ Persons with Autism } & \multirow[b]{2}{*}{$t$} & \multirow[b]{2}{*}{$p$} & \multirow[b]{2}{*}{$d f$} \\
\hline & $n$ & $M$ & $S D$ & $n$ & $M$ & $S D$ & & & \\
\hline \multicolumn{10}{|l|}{ Gender } \\
\hline Female & 15 & & & 9 & & & & & \\
\hline Male & 13 & & & 16 & & & & & \\
\hline \multicolumn{10}{|l|}{ Handedness } \\
\hline Right & 25 & & & 23 & & & & & \\
\hline Left & 3 & & & 2 & & & & & \\
\hline Age & 28 & 41.32 & 9.86 & 25 & 34.54 & 10.04 & 2.32 & $.022 * *$ & 51 \\
\hline $\begin{array}{l}\text { Educational } \\
\text { Years }\end{array}$ & 25 & 18.18 & 5.6 & 24 & 17.7 & 3.98 & .337 & .737 & 47 \\
\hline AQ & 27 & 22.11 & 6.19 & 25 & 39.08 & 5.27 & 10.61 & $<.001 * * *$ & 50 \\
\hline EQ & 26 & 43.88 & 9.87 & 25 & 15.6 & 8.58 & -10.9 & $<.001 * * *$ & 49 \\
\hline
\end{tabular}

Note. $n=$ number of subjects; $M=$ mean; $S D=$ standard deviation; $t=\mathrm{t}$ distribution; $p=$ probability; $d f=$ degrees of freedom; $\mathrm{AQ}=$ Autism-Spectrum Quotient (Baron-Cohen, Wheelwright, Skinner, et al., 2001); EQ = Empathy Quotient (Baron-Cohen \& Wheelwright, 2004); * $p<.05 ; * * p<.01$; *** $p<.001$.

\subsection{Material}

A new set of stimuli was created to address both mood and action recognition skills. Stimuli were recently generated by Lammers and Geiger (Lammers, 2017), mainly to examine mirroring and mentalizing in future functional magnetic resonance imaging studies. Using motion capture techniques, they asked volunteers to perform every day movements (i.e. mopping or sweeping the floor) while putting themselves in different emotional states (i.e. happy or angry). Subsequently the resulting genuinely human movements were mapped onto a genderless mannequin without any facial attributes to reduce distraction or any possibly confounding influence of visible characteristics, like gender, ethnicity or sex. The systematic use of computer animation techniques is suggested to offer a wide potential in research concerning communication and social impressions (Bente \& Krämer, 2001). It has been pointed out that such virtual characters can be especially valuable in investigating nonverbal communication in autism (Georgescu, Kuzmanovic, Roth, 
Bente, \& Vogeley, 2014) as they combine high experimental control and ecological validity (Vogeley \& Bente, 2010).

In a first step the physical characteristics of the videos were extensively tested. For the objective analysis of the kinematic trajectories an algorithm focusing on pixel intensity and the size of a region of interest (the amount of space taken by the avatar in the video) detected deviating characteristics in the videos, namely outliers in movement frequency or speed. After excluding concerned ones from the dataset, remaining videos showed high similarity concerning their psychophysical characteristics (luminance, pixel change, movement trajectories).

In a second step of the selection process, a perception analysis was carried out to have the residual 83 videos assessed by naïve raters. 112 volunteers $(73$ females, mean age $=31.66, \mathrm{SD}=$ 11.71) were recruited for the behavioral survey that was conducted online via Unipark (Questback $\mathrm{GmbH}$, EFS Survey, Version 10.9, http://www.unipark.com). Its aim was to investigate the recognition rates for the individual videos in each condition. Detection rates in both conditions were similarly spread, indicating that most videos were rated above chance level in a range from mostly 60 to 100 percent correct recognition in one of the two conditions. 32 videos that showed similar recognition rates for both mood and action were chosen for the final set of stimuli. Accordingly, a stimulus set with homogeneous psychophysical properties and similar detection rates for both variables of interest remained. Every animated video sequence contained information about the performed action and the mood during the movement.

Two different movements (mopping and sweeping) and two different moods (happy and angry) varied in the resulting collection of video sequences, leading to a division into four subgroups: (a) happy swiping, (b) happy mopping, (c) angry swiping, (d) angry mopping. Each group consisted of 8 videos. Since all videos were to be rated on both contained information, two conditions were defined: mood recognition, referring to mirroring abilities and action recognition, addressing mentalizing abilities. A full run, including all 32 videos thus consisted of 64 trials. For a more detailed description of the development of the stimuli see (Lammers, 2017).

The presented stimuli are suitable for various experiments on the human social brain. Until today they were used in a fMRT study by Alexander Geiger (manuscript in preparation) and the study at hand. For the latter the, the movie clips were adopted and bedded in a behavioral study to investigate mood and action recognition skills of control participants and a clinical population. The resulting experiment was created and presented with PsychoPy, a software for Python (Python 
Software Foundation, Version 2.7.15, https://www.python.org/) and installed on a desktop computer.

Next to the main test on the computer, two paper pencil questionnaires were used. Severity of autistic traits was measured using the Autism-Spectrum Quotient (Baron-Cohen, Wheelwright, Skinner, et al., 2001) and an empathy score was recorded using the Empathy Quotient (BaronCohen \& Wheelwright, 2004) to investigate possible correlations between scores on these scales and deviant behavior of the patient group. The whole study was conducted in German.

\subsection{Procedure}

The experiment was conducted on a desktop computer in a laboratory of the university clinic Cologne. Before the start of the experiment an oral and written introduction was given to the participant explaining the exact procedure of the experiment. The two possible conditions of the experiment were achieved by presenting one of two rules (mood vs. action observation) on what to pay attention to in the clip. Following the indication of the rule, one of the 32 possible videos was displayed for 5 seconds. The order of the displayed videos and the assigned rules were counterbalanced. Each video was presented twice, once with the instruction to observe the action and once to observe the mood displayed. Participants subsequently had to choose between the two possible options of the indicated category, meaning (a) mopping vs. sweeping after action observation or (b) happy vs. angry after mood observation. The two alternatives were displayed on the left-hand and on the right-hand side of the computer screen. Answers were given by using two designated buttons on the keyboard. The left button ("c") was used to select the option shown on the left-hand side of the screen, the right button ("m") for the option shown on the right. The positions of both options were counterbalanced. An answer could be given within a time frame of three seconds. Since this study was not intended to be a reaction time experiment, this time frame was considered sufficient and appropriate. This duration was chosen to give participants enough time for their responses without provoking long reflection times or risking an interruption in case of long indecisiveness. After the three second window for the answer, a three second pause and the display of a fixation cross for two seconds followed automatically, before the next trial started. Answers could therefore only be recorded, if given during this three second frame. If no answer was given in time, the experiment proceeded nevertheless. In figure 2 the procedure is presented visually. 


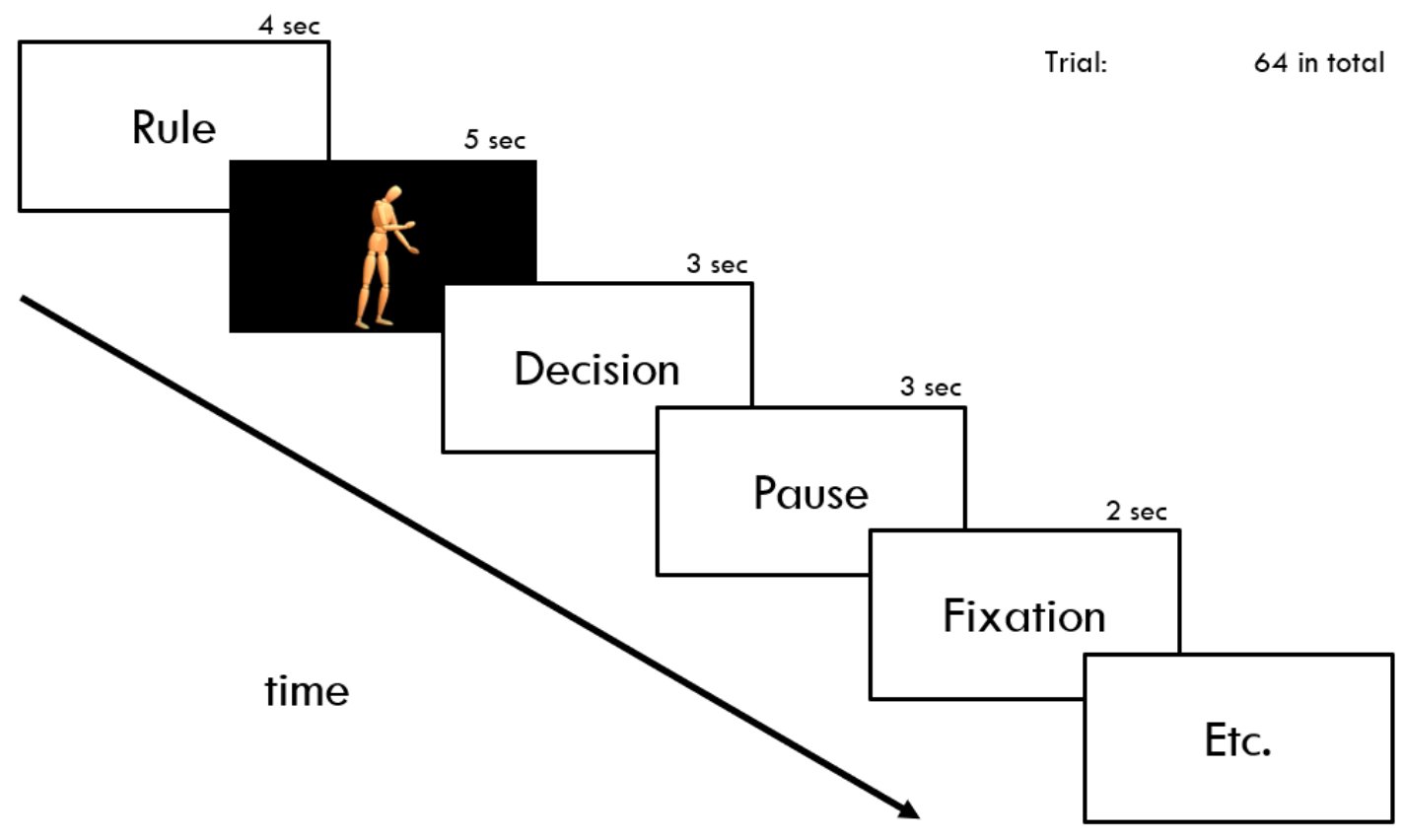

Figure 2. Schematic overview of the experiment. Rule indicated either mood or action (condition). The decision was subject to the established rule.

After completing the study on the computer, the previously described paper pencil questionnaires, namely AQ and EQ, were handed out and several demographic information, including age and years of education were collected. Eventually, a short debriefing was given to inform participants about the purpose and the theoretical background of the study.

\subsection{Analysis}

Data were analyzed using R (R Development Core Team, 2011), RStudio (RStudio Team, 2016) and IBM SPSS Statistics Version 24. To compare participants demographic and questionnaire data, linear regressions were calculated in SPSS. For the main analysis, structured data for mood and action recognition were analyzed in generalized linear mixed effects models using the glmer() function from the lme4 package (Bates, Mächler, Bolker, \& Walker, 2015) in R. Effect sizes were estimated considering odds ratio values and interpreted according to relevant literature (Chen, Cohen, \& Chen, 2010; Chinn, 2000). For detailed comparisons of the 
performance on both scales within and between the groups single t-tests were conducted. Correlations were calculated between the performance in mood and action recognition and scores on AQ and EQ in SPSS.

The main reason to use mixed effects models to analyze the available data was their suitability for repeated measurement designs with non-continuous variables. They are suggested to deal with potentially confounding covariates and missing values in a more appropriate fashion than ANOVAs (Gueorguieva \& Krystal, 2004; Kliegl, 2010) and to be more balanced and conservative (Quené \& van den Bergh, 2008). The lme4 package allowed to examine interindividual differences between participants response behavior as random intercepts (Bates, Mächler, Bolker, \& Walker, 2014). Without having to shorten or summarize the data set, the influence of the individual participants could therefore be included in the analysis. Mixed effect models are usually built up successively, starting from a null-model that only contains a fixed intercept and a random factor. In this case the different subjects represented the random factor. Gradually, the predictors (rule and group) and their interaction were included (ordered: rule, group, rule * group). Resulting models were compared with an analysis of deviance. This calculation enables to determine AIC (Akaike information criterion), BIC (Bayesian information criterion) and log-likelihood which serve as measures for goodness of fit and enable to investigate influences of predictors and their interactions. A type one error rate smaller than five percent is stipulated. Trials in which no answer was given, were treated as incorrect answers.

\section{Results}

28 healthy participants and 25 persons with autism took part in this study. The difference in age between groups reached statistical significance, $t(51)=2.316, p=.022$.

Examining the data, two outliers were detected in the group of controls. In the condition addressing action recognition skills one subject's mean correctness lay more than two standard deviation apart from the mean. In the condition addressing mood recognition skills another subject's mean correctness lay more than two standard deviations apart from the mean. Reasons for maintaining and for excluding those subjects were carefully weigh out against one another. Possibly, concerned participants were tired, unmindful or did not understand the task properly. Since the study was the first to utilize the new stimulus set in an event-related context to examine the performance of two different groups, no data to compare the results to were available. Thus, 
no knowledge about the distribution of data had been acquired yet. It was decided to maintain the data of both participants for further analysis. Doing so, the dataset could be examined in it's full. A separate analysis showed that results without those outliers did not differ from the main analysis. To investigate a possible influence of age and gender, linear regressions were calculated. Because the detection rates for neither movements nor mood were significantly correlated with age (all $r$ 's $\leq 0.01$, all $p$ 's $\geq .48$ ), age was excluded from any further analyses. Gender did not have any influence on the detection rate as well (all $t$ 's $\leq 0.111$, all $p$ 's $\geq .912$ ). Also, when both groups were examined separately, no correlations of age or gender were found.

Further statistical analysis were conducted using general linear mixed effects models with the glmer() function. A null model was established in order to build upon it. The first and most simple model only included the different conditions ("Rule") as fixed effects. The second model additionally included the diagnostic group ("Group"). The third and last model included an analysis of the interaction of Rule and Group. In the following the models are listed as functions (Bates et al., 2014; Wollschläger, 2015). Portrayed are the depended variables on the left and the regressors on the right side of the tilde $(\sim)$. A "+" stands for an additive effect. A "**" for an interaction effect. Random effects are indicated in parentheses behind "|" as the grouping factor. In the first model, the null model, no variables are included besides the individual subject as a random effect.

Model 0: Detection rate $\sim+1+(1 \mid$ Subject $)$
Model 1: Detection rate $\sim$ Rule $+(1 \mid$ Subject $)$
Model 2: Detection rate $\sim$ Rule + Group $+(1 \mid$ Subject $)$
Model 3: Detection rate $\sim$ Rule $*$ Group $+(1 \mid$ Subject $)$ 
An analysis of deviance that compared all 4 models is mapped in table 2. According to the calculated values for AIC and BIC, the model including rule and group as fixed effects was considered the best fitting model to describe the dataset. Adding the interaction between rule and group as a predictor did not significantly improve the model fit. According to the value for deviance, the interaction does fit better, but this improvement is not statistically significant, and $\mathrm{AIC}$ and BIC indicate, that the less complex model 2 fits the data best.

For both rule and group significant main effects could be found. The odds of a correct answer in the action recognition task were 1.36 times the odds of a correct answer for mood recognition $\left(S E=0.08, X^{2}(1)=16.72, p<.001\right)$. For the fixed factor group it was identified, that the odds for a correct detection in the group of controls were 1.53 times the odds of a correct answer in the group of persons with autism $\left(S E=0.14, X^{2}(1)=9.01, p=.003\right)$. According to Chen, Cohen and Chen (2010) this equals a small effect for rule and a small to medium effect for group, respectively. To illustrate the findings, boxplots in Figure 3 show the detection rates of participants according to diagnostic group and rule. Detection rates were calculated for each subject individually and separated by condition, by relating the number of correctly answered trials to the total of trials in this condition.

Table 2

General linear mixed effects models

\begin{tabular}{lllllllll}
\hline & $D f$ & AIC & BIC & logLik & deviance & Chisq & Chi Df & Sig. \\
\hline Null-model & 2 & 4148.1 & 4260.3 & -2072.1 & 4144.1 & & & \\
Rule & 3 & 4133.4 & 4151.8 & -2063.7 & 4127.4 & 16.72 & 1 & $<.001^{* * *}$ \\
Rule + Group & 4 & 4126.4 & 4150.9 & -2059.2 & 4118.4 & 9.01 & 1 & $.003^{* *}$ \\
Rule * Group & 5 & 4127.6 & 4158.3 & -2058.8 & 4117.6 & 0.74 & 1 & .390 \\
\hline
\end{tabular}

Note. ${ }^{*} p<.05 ; * * p<.01 ; * * * p<.001$. 


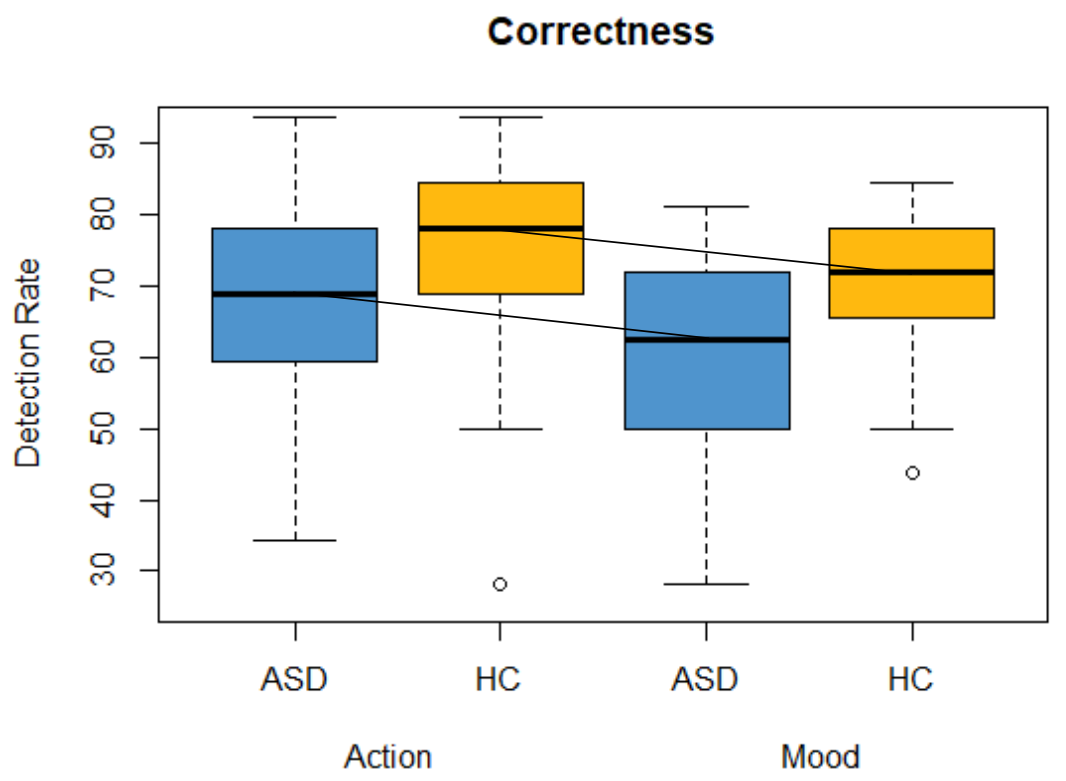

Figure 3. Boxplot displaying detection rate as a function of group in mood and action recognition condition. Detection rates were aggregated for the individual subjects and transferred to percentage values. Medians of detection rates are marked by thick black lines. Medians of both conditions in one group are connected. A visible difference can be seen between groups, especially in mood recognition. Within the groups a difference can be seen between the two given rules.

For an easier understanding of the results in connection with previously established hypotheses, t-test analysis will be presented in the following. With post hoc t-tests same results can be observed. The first hypotheses suspected a significant difference between mood and action recognition in persons with autism when both are addressed with the same visual input, which was analyzed with a paired sample t-test. According to the data persons with autism perform significantly better in action detection than in mood detection $(t(24)=2.514, p=.019)$. As hypotheses 2 suspected no differences in the detection performance for mood and action recognition was observed in controls $(t(27)=1.399, p=.173)$.

Comparing the two diagnostic groups, the third hypotheses suggested that persons with autism and controls differ in their ability to recognize emotions with a better performance in controls. Concerning mood detection a difference was observed $(t(51)=-3.028, p=.004)$. As hypotheses 4 claimed, persons with autism performed as well as $\mathrm{HC}$ in action detection. No significant difference was visible $(t(51)=-.858, p=.069)$.

In general, a significant difference was found between the two possible rules, addressing mood and action recognition skills $(t(52)=2.719, p=.009)$. 
Hypotheses 5 to 8 considered the correlations between scores in the AQ and EQ and the performance in the study. Linear regression calculated for the connection between AQ and the correctness in action detection showed significant results $(t=-3.107, p=.003)$, as well as between AQ and the correctness in mood detection $(t=-2.824, p=.007)$. This suggests that a higher score in this questionnaire is related to a smaller recognition rate of action and mood, respectively. However, when separated into diagnostic groups, no correlation could be found (all $r$ 's $\leq 0.057$, all $p$ 's $\geq .261$ ). No relations could be detected between the score on the EQ and the recognition performance for action or mood (all $r$ 's $\leq 0.133$, all $p$ 's $\geq .227$ ).

Looking at the data, it also became apparent that many trials remained unanswered, especially in the autism group. On average $4,87 \%$ of trials for action and $10,75 \%$ for $\operatorname{mood}$ recognition were not answered in this group. Controls missed 1,34\% in the condition for action and $1,45 \%$ in mood recognition on average. These "misses" were therefore also examined in more detail. For an easier understanding of, those misses are visualized in figure 3. Again, general linear mixed effect models were calculated like described previously. This time, trials that remained unanswered were not coded as a false answer, but as a missing value. The detection rate thus differed from the first analysis. Table 3 displays the results of the analysis of deviance.

Misses

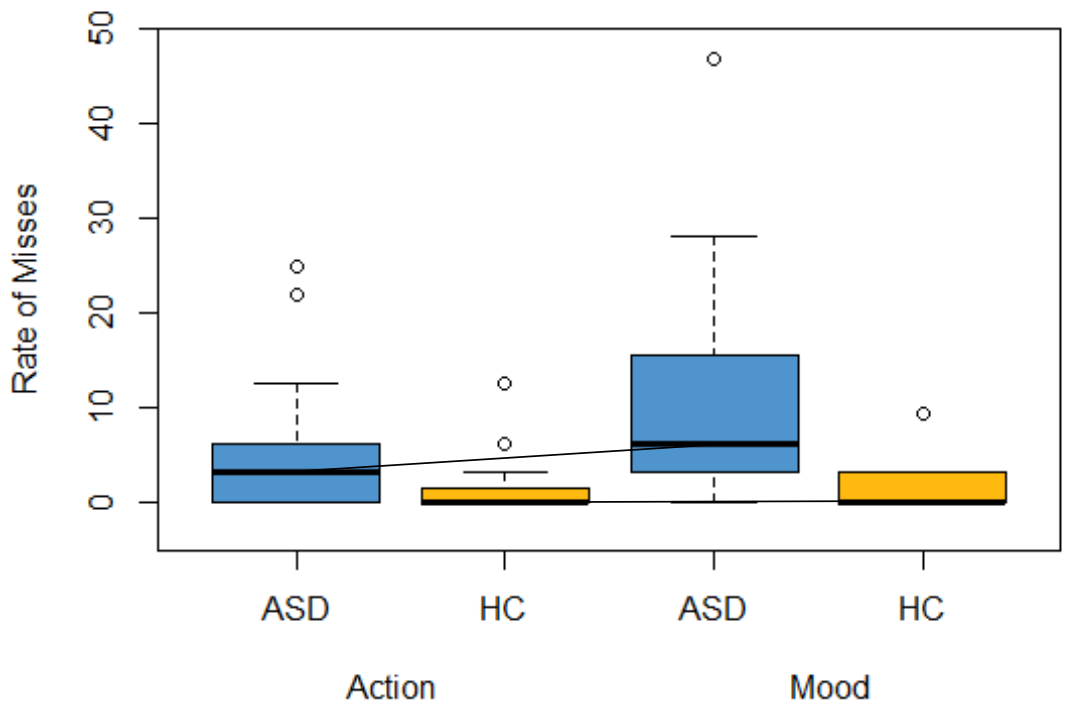

Figure 4. Boxplot displaying unanswered trials (misses) as a function of group in mood and action recognition condition. Detection rates were aggregated for the individual subjects. Medians of detection rates are marked by thick black lines which are connected for both conditions in one group. Especially in mood recognition in autism a higher rate of misses was observed. 
Comparing all models with an analysis of deviance without calculating in misses, the first model, only including rule and random effects, emerges as the best fitting model. Although AIC, log likelihood and deviance show better values, the second model (rule + group) does not predict the data significantly better. Adding the interaction between rule and group as a predictor also does not lead to any improvement in model fit. Only the condition "rule" is thus to keep as a fixed effect in the model.

In this case, the odds for a correct answer in the action recognition task were 1.27 times the odds of a correct answer in the mood recognition condition $\left(S E=0.08, X^{2}(1)=9.02, p=.003\right)$. This equals a small effect for the fixed effect rule.

Table 3

General linear mixed effects models excluding unanswered trials

\begin{tabular}{lllllllll}
\hline & Df & AIC & BIC & logLik & deviance & Chisq & Chi Df & Sig. \\
\hline Null-model & 2 & 3817.8 & 3829.9 & -1906.9 & 3813.8 & & & \\
Rule & 3 & 3810.7 & 3829.0 & -1902.4 & 3804.7 & 9.02 & 1 & $.003 * *$ \\
Rule + Group & 4 & 3809.4 & 3833.8 & -1900.7 & 3801.4 & 3.31 & 1 & .069 \\
Rule * Group & 5 & 3811.4 & 3841.8 & -1900.7 & 3901.4 & 0.02 & 1 & .891 \\
\hline
\end{tabular}

Note. $* p<.05 ; * * p<.01 ; * * * p<.001$.

To find out more about the misses, separate generalized linear mixed effects models were calculated. The procedure stayed the same. In table 4 results of the analysis of deviance are displayed.

Table 4

General linear mixed effects models of missed trials

\begin{tabular}{lllllllll}
\hline & Df & AIC & BIC & logLik & deviance & Chisq & Chi Df & Sig. \\
\hline Null-model & 2 & 1101.6 & 1113.8 & -548.79 & 1097.6 & & & \\
Rule & 3 & 1085.8 & 1104.2 & -539.90 & 1079.8 & 17.77 & 1 & $<.001 * * *$ \\
Rule + Group & 4 & 1066.7 & 1091.2 & -527.70 & 1055.4 & 3.29 & 1 & $<.001 * * *$ \\
Rule * Group & 5 & 1065.4 & 1096.0 & -527.70 & 1055.4 & 3.29 & 1 & .0697 \\
\hline
\end{tabular}

Note. $* p<.05 ; * * p<.01 ; * * * p<.001$. 
Considering AIC, the model including the interaction term (rule * group) is the best fitting model. However, considering the value of $\mathrm{BIC}$, the model comprising rule and group is found to fit the data best, while values for log-likelihood and deviance do not differ between those models. The more conservative model is thus chosen to explain the data. For both rule and group a main effect could be found on a significance level of .05 . The odds of miss in the action recognition task were 0.40 times the odds of a miss for mood recognition, which means that the odds for a miss in mood were 2.5 times the odds for a miss in action detection $\left(S E=-0.92, X^{2}(1)=17.77, p<.001\right)$. For the fixed factor group it was identified, that the odds for a miss in the autism group were 8.52 times the odds of a miss in the group of controls $\left(S E=0.43, X^{2}(1)=21.11, p<.001\right)$. According to Chen et al. (2010) this equals a small to medium effect for rule and a large effect for group, respectively.

It can be summarized that the main hypotheses can be maintained. However, during the analysis, a difference in the amount of unanswered trials was discovered. Relations between scores on the questionnaires AQ and EQ and the performance of the study could not be found, or only across the groups. Implications of these findings will be discussed in the following.

\section{Discussion}

The objective of this study was to compare the detection performance of actions and emotions in persons with autism and controls. Never before have these skills been assessed in such a way as to allow direct comparisons. Only now, using a very recently developed set of stimuli it was possible to address both abilities separately with the same visual input. The stimuli have never been used with a clinical population before. Therefore, the current study allowed new insights into action and mood detection skills that relate to mirroring and mentalizing abilities. The comparison between a control group and persons with autism in addition revealed new and interesting information about the disease. This information could change the picture of the disease and may help to find a better treatment for those affected.

25 persons with autism and 28 controls participated in the study. It was to be investigated if there is a difference in recognition rates between both groups and if the performances differ between both conditions, concerning mirroring or mentalizing tasks. It was assumed that people with autism do worse in the condition in which emotion should be observed, but that there are no performance differences in the condition of motion recognition. The main analysis considered the 
ratio of correctly given answers to the total of runs. The results indicate major effects for the condition as well as for the group. Thus, participants scored better when it came to mirroring compared to mentalizing. Overall, controls performed better than persons with autism. As previously suggested, a significant difference between mirroring and mentalizing performance was observed in autism, whereas no difference appeared in controls. This suggests that both skills usually are equally well developed. The ability to recognize another person's emotional state appears impaired in autism. The recognition of movements however is not affected by the disease, which speaks against the so-called "broken-mirror hypotheses" which was assumed a few years ago (Ramachandran \& Oberman, 2006).

A suspected interaction did not turn out significant. However, a tendency towards an interaction appeared visible. In the later executed analysis of misses this tendency was very clear and marginally significant.

A genuine difference between the abilities to mirror and to mentalize another person's appearance was detected by this study using appropriate experimental stimuli. Consequently, it can be deducted, that performance of those two features can differ greatly within one individual. For the clinical subgroup of the sample, a significant difference between mirroring and mentalizing performance was observed, whereas mentalizing appeared to be more difficult for persons with autism. Since only this single function shows impairments in autism, a possible rational interpretation of these findings includes the assumption that both abilities are largely independent from each other. However, those abilities still could be connected, which could explain the main effect of the group in the current findings. Also, in mirroring, HC performed better, although this difference did not turn out to be statistically significant. Since both abilities deal with the observance of other people, an anomaly of one of them could trigger the lack in development of the second ability. The entangling of both skills is difficult to manage in one single behavioral experiment. Further research, including neurophysiological methods is necessary to properly distinguish the functions and associated brain activation pattern. Concrete conclusions about the systems behind mirroring and mentalizing skills thus cannot be drawn. However, presented considerations can cautiously be transferred to the brain regions and neural networks that were presented before (Figure 1, chapter 5.2.3) Assumingly, persons with autism have no or only slight impairments in the system responsible for mirroring, thus the MNS. The system providing mentalizing functions on the other hand, MENT, seems to be more affected by the disorder. 
Available data only allows speculation about the synergy of both constructs in autism. Future research, especially utilizing imaging techniques is required to be able to draw substantial conclusions about core brain regions of mirroring and mentalizing, particularly in autism.

Since the number of misses caught the eye during the analysis, data were evaluated more closely. A new analysis was set up that presented the ratio of correctly answered trails to the total amount of trials, excluding unanswered trials. Differences between groups vanished. A main effect of rule still could be observed. Apparently, the observation condition, so the request to either concentrate on the action or the mood displayed, still had an unambiguous influence on the correctness. The recognition of movements still was easier than the detection of the mood the action was performed in. Only speculations can be put forward about the possible causes of this observation. Thereby it should be borne in mind that a time frame of three seconds was given to choose between the two possible alternatives. Thus, this was not an experiment with a focus on reaction time. Especially considering the five second display of the video during which a decision could already be prepared to only assign it to the correct side of the screen afterwards. It can thus be assumed that participants were not under any pressure of time. However, this cannot be said with certainty, because participants were not asked about the reasons for not answering after the experiment.

Misses were observed separately later. It was determined that the number of misses indeed was significantly higher in the group of persons with autism. Especially in the mentalizing condition the rate of misses was significantly higher in autism. As figure 4 (chapter 7) indicates, results for the rates of misses were apparently nearly inverted to the correctness. A marginal significant interaction was visible. Although the results are difficult to interpret, they allow the assumption that mentalizing is harder than mirroring for persons with autism, which can be related to the associated brain areas of MNS and MENT again, stipulated greater anomalies in the MENT. The observation of a higher number of misses and the fact that the differences in correctness between groups disappeared when those misses were left out of the analysis, is highly interesting. Values for performance of persons with autism were comparable to those of $\mathrm{HC}$ if difficult trials were dropped. The next question coming to mind is, whether participants, mainly those with autism, only then chose to press a key, if they were sure with their decision and if they preferred not to answer if they were unsure. Boulter, Freeston, South, and Rodgers (2014) described intolerance of uncertainty as a relevant construct in autism. Based on this it appears plausible that more trials 
remained unanswered in the autism group, because members rather avoided the decision than giving a wrong response. To deal with this possible problem seems difficult. A third option ("I don't know") could be given, leaving the participants an option to cope with their uncertainty. Doing so more members of the control group probably would also choose this option frequently. A comparison of both groups and conditions thus would still be ambiguous. An alternative explanation for the high number of misses could be the window of time to give an answer, which might have been too small to make a sure decision. Thereby it should be borne in mind that a time frame of three seconds was given to choose between the two possible alternatives. Thus, this was not an experiment with a focus on reaction time. Especially considering the five second display of the video during which a decision could already be prepared to only assign it to the correct side of the screen afterwards. It can thus be assumed that participants were not under any pressure of time. However, this cannot be suspected with certainty, because participants were not asked about their reasons for not answering a trial after the experiment. The time frame was chosen to ensure a smooth procedure of the experiment and to obtain intuitive responses. Possibly the performance of the autism group would have been better if there had been infinitely much time available. Results excluding missed trials speak for this assumption. Some authors argue that due to impairments in executive functioning, perception or processing of information is slowed in ASD (Kaiser \& Pelphrey, 2012). Thus, the visual input from the presented videos would take longer to be properly processed and rated by individuals with autism. Offering a longer time for the decision however would not lead to any additional information for the participants. If the assumption was true that persons with autism process information slower due to anomalies in executive functions this would be true for both conditions of the present study. Since there is not infinite time for decisions in real-life, a smaller window of time additionally is more realistic. Both were realized with the exact same visual input. According to Ferraro (2016) choice reaction is not decelerated in autism which speaks against this suggestion. Participants of this study were not instructed to answer as quickly as possible. The available time frame was explained, but it was emphasized that their reaction time did not matter. Because no explicit order was given concerning the speed of answering, reaction time could not be analyzed. To investigate if the time frame played an eminent role for the differences in performance between both groups another experiment would be necessary. 
Concerning the results of the questionnaires AQ and EQ one could have thought that there is a correlation between scores on these scales and the performance in the experiment. The AQ however does not serve to quantify the expression of the disorder. It also is not a diagnostic tool but helps to scan for autistic traits. A connection between the score and the performance in mentalizing in autism was suggested and a tendency towards this assumption could be observed. For a significant result the sample size probably was not big enough, since the scattering of values for the rate of correct answers is much higher that the distribution of scores on the AQ in the group of ASD. Similar explanations can be applied to findings on the EQ.

The estimated effect sizes did not turn out very large. Several potential causes can be named. First of all, the sample size should be taken in consideration. A number of participants of 53 is usual for an experiment with a clinical population. Of course, higher effect sizes could be reported if more participants would have been tested. Since an experiment like this could mean a stressful experience, especially for participants with a clinical diagnosis of ASD, an unnecessary high number of participants should not be invited. All participants for the autism group were diagnosed at professor Vogeley's outpatient clinic for autism in adulthood. Members of this group thus represent a specific subgroup of the autistic population. All of them were not diagnosed until adulthood, which speaks for above-average cognitive performance that facilitates compensatory mechanisms. Possibly results would appear clearer, if not only participants of the high functioning subgroup of autism were included. The chosen sample however allowed to compare two groups that did not differ but in autistic symptoms. Differences in performance could thus be ascribed to differently pronounced features which simplifies interpretation of results. With a less controlled sample, there would have been additional attributes that would have been necessary to take into account during the calculations, such as cognitive abilities. Also, in a younger sample larger differences could be possible. This cannot be answered with the available data. Another study to take up this question would be necessary for this purpose. Also, it would be highly interesting, to repeat similar testings with other diseases, like attention deficit hyperactivity disorders (ADHS). Since it often comes to difficulties in the differential diagnosis between ASD and ADHS, the design of the study at hand to provide a new feature with which comparison groups could be divided. But also, other clinical populations should be tested for mirroring and mentalizing skills to probe the social brain. Another challenge in research in this area lays in the fact that not only one person's neuropsychology is of interest in every social encounter, but that at least two person's behaviors 
are to be examined. Consequently online procedures are highly interesting and offer insight in the co-regulation of reciprocal actions (Sperduti, Guionnet, Fossati, \& Nadel, 2014). Examining alignment on tasks addressing both MNS and MENT between two persons thus would lead to an immense increase in knowledge about the human social brain. How this can be managed remains an interesting open question.

\section{Conclusion}

In this study, recognition rates for movements and emotions were examined within persons with autism and controls. Therefore, a new stimulus set, controlling for potentially confounding variables was used that proofed to serve its cause. Mirroring and mentalizing skills were to be addressed separately with the same input, which succeeded. Groups differed in recognition performance in both conditions, especially in mentalizing. Mentalizing seemed to be more difficult, especially for persons with autism. Interestingly misses seemed to represent impairments in autism as well as the correctness of detection. Dropping unanswered trials, persons with autism performed as well as controls. Several questions remain unanswered or emerged from the presented results, opening doors to further research on the human social brain. Particularly the probable independence of both abilities and associated neural networks, but also their synergy is to be investigated in detail. 


\section{Acknowledgements}

I would like to thank my supervisor Prof. Dr. Dr. Kai Vogeley for the extraordinary opportunity to be part of his work group and such an interesting project in particular; Alexander Geiger for his marvelous mentoring, support and his numerous indispensable advices; Mathis Jording for his patience and time, giving me new insights in methodology and statistical analyses; Sebastian Lammers for stimulating discussions and for always openly answering my questions, especially about his work on the used stimuli and everyone involved in the project, including testing, postprocessing and inspiring remarks during the process of writing this thesis. 


\section{References}

American Psychiatric Association, \& American Psychiatric Association (Eds.). (2013).

Diagnostic and statistical manual of mental disorders: DSM-5 (5th ed). Washington, D.C: American Psychiatric Association.

Arbib, M. A. (2005). From monkey-like action recognition to human language: An evolutionary framework for neurolinguistics. Behavioral and Brain Sciences, 28(2), 105-124. https://doi.org/10.1017/S0140525X05000038

Baird, A. D., Scheffer, I. E., \& Wilson, S. J. (2011). Mirror neuron system involvement in empathy: A critical look at the evidence. Social Neuroscience, 6(4), 327-335. https://doi.org/10.1080/17470919.2010.547085

Baron-Cohen, S. (2000). Theory of mind and autism: A review. In International Review of Research in Mental Retardation (Vol. 23, pp. 169-184). Elsevier. https://doi.org/10.1016/S0074-7750(00)80010-5

Baron-Cohen, S. (2001). Theory of mind and autism: A review. International review of research in mental retardation, 23(23), 169-184.

Baron-Cohen, S., Leslie, A. M., \& Frith, U. (1985). Does the autistic child have a "theory of mind" ? Cognition, 21(1), 37-46. https://doi.org/10.1016/0010-0277(85)90022-8

Baron-Cohen, S., \& Wheelwright, S. (2004). The Empathy Quotient: An Investigation of Adults with Asperger Syndrome or High Functioning Autism, and Normal Sex Differences. Journal of Autism and Developmental Disorders, 34(2), 163-175. https://doi.org/10.1023/B:JADD.0000022607.19833.00

Baron-Cohen, S., Wheelwright, S., Hill, J., Raste, Y., \& Plumb, I. (2001). The "Reading the Mind in the Eyes" Test Revised Version: A Study with Normal Adults, and Adults with 
Asperger Syndrome or High-functioning Autism. The Journal of Child Psychology and Psychiatry and Allied Disciplines, 42(2), 241-251.

https://doi.org/10.1017/S0021963001006643

Baron-Cohen, S., Wheelwright, S., Skinner, R., Martin, J., \& Clubley, E. (2001). The AutismSpectrum Quotient (AQ): Evidence from Asperger Syndrome/High-Functioning Autism, Malesand Females, Scientists and Mathematicians. Journal of Autism and Developmental Disorders, 31(1), 5-17. https://doi.org/10.1023/A:1005653411471

Bates, D., Mächler, M., Bolker, B., \& Walker, S. (2014). Fitting Linear Mixed-Effects Models using lme4. ArXiv:1406.5823 [Stat]. Retrieved from http://arxiv.org/abs/1406.5823

Bates, D., Mächler, M., Bolker, B., \& Walker, S. (2015). Fitting Linear Mixed-Effects Models Using Ime4. Journal of Statistical Software, 67(1). https://doi.org/10.18637/jss.v067.i01

Becchio, C., Cavallo, A., Begliomini, C., Sartori, L., Feltrin, G., \& Castiello, U. (2012). Social grasping: From mirroring to mentalizing. NeuroImage, 61(1), 240-248. https://doi.org/10.1016/j.neuroimage.2012.03.013

Bente, G., \& Krämer, N. C. (2001). Psychologische Aspekte bei der Implementierung und Evaluation nonverbal agierender Interface-Agenten. In Mensch \& Computer 2001 (pp. 275-285). Vieweg+Teubner Verlag. https://doi.org/10.1007/978-3-322-80108-1_29

Bertone, A., Mottron, L., Jelenic, P., \& Faubert, J. (2003). Motion Perception in Autism: A “Complex” Issue. Journal of Cognitive Neuroscience, 15(2), 218-225. https://doi.org/10.1162/089892903321208150

Bishop, D. V. M., \& Norbury, C. F. (2005). Executive functions in children with communication impairments, in relation to autistic symptomatology: I: Generativity. Autism, 9(1), 7-27. https://doi.org/10.1177/1362361305049027 
Boulter, C., Freeston, M., South, M., \& Rodgers, J. (2014). Intolerance of Uncertainty as a Framework for Understanding Anxiety in Children and Adolescents with Autism Spectrum Disorders. Journal of Autism and Developmental Disorders, 44(6), 1391-1402. https://doi.org/10.1007/s10803-013-2001-X

Boyatzis, C. J., \& Satyaprasad, C. (1994). Children's facial and gestural decoding and encoding: Relations between skills and with popularity. Journal of Nonverbal Behavior, 18(1), 3755. https://doi.org/10.1007/BF02169078

Brooks, R., \& Meltzoff, A. N. (2015). Connecting the dots from infancy to childhood: A longitudinal study connecting gaze following, language, and explicit theory of mind. Journal of Experimental Child Psychology, 130, 67-78. https://doi.org/10.1016/j.jecp.2014.09.010

Buccino, G., Binkofski, F., Fink, G. R., Fadiga, L., Fogassi, L., Gallese, V., ... Freund, H.-J. (2008). Action observation activates premotor and parietal areas in a somatotopic manner: an fMRI study. European Journal of Neuroscience, 13(2), 400-404. https://doi.org/10.1111/j.1460-9568.2001.01385.x

Castelli, F., Frith, C., Happé, F., \& Frith, U. (2002). Autism, Asperger syndrome and brain mechanisms for the attribution of mental states to animated shapes. Brain, 125(8), 18391849. https://doi.org/10.1093/brain/awf189

Chen, H., Cohen, P., \& Chen, S. (2010). How Big is a Big Odds Ratio? Interpreting the Magnitudes of Odds Ratios in Epidemiological Studies. Communications in Statistics Simulation and Computation, 39(4), 860-864. https://doi.org/10.1080/03610911003650383 
Chinn, S. (2000). A simple method for converting an odds ratio to effect size for use in metaanalysis. Statistics in Medicine, 19(22), 3127-3131. https://doi.org/10.1002/10970258(20001130)19:22<3127::AID-SIM784>3.0.CO;2-M

Cochin, S., Barthelemy, C., Roux, S., \& Martineau, J. (1999). Observation and execution of movement: similarities demonstrated by quantified electroencephalography. European Journal of Neuroscience, 11(5), 1839-1842. https://doi.org/10.1046/j.14609568.1999.00598.x

Csibra, G. (2008). Action mirroring and action understanding: An alternative account. Sensorymotor foundations of higher cognition. Attention and performance XXII, 435-459.

de Lange, F. P., Spronk, M., Willems, R. M., Toni, I., \& Bekkering, H. (2008). Complementary Systems for Understanding Action Intentions. Current Biology, 18(6), 454-457. https://doi.org/10.1016/j.cub.2008.02.057

Deutsche Gesellschaft für Kinder- und Jugendpsychiatrie, Psychosomatik und Psychotherapie (DGKJP). (2016). Autismus-Spektrum-Störungen im Kindes-, Jugend- und Erwachsenenalter Teil 1: Diagnostik Interdisziplinäre S3-Leitlinie der DGKJP und der DGPPN sowie der beteiligten Fachgesellschaften, Berufsverbände und Patientenorganisationen.

Dinstein, I., Thomas, C., Behrmann, M., \& Heeger, D. J. (2008). A mirror up to nature. Current Biology, 18(1), R13-R18. https://doi.org/10.1016/j.cub.2007.11.004

Dinstein, I., Thomas, C., Humphreys, K., Minshew, N., Behrmann, M., \& Heeger, D. J. (2010). Normal Movement Selectivity in Autism. Neuron, 66(3), 461-469. https://doi.org/10.1016/j.neuron.2010.03.034 
Ferrari, P. F., \& Rizzolatti, G. (2014). Mirror neuron research: the past and the future. Phil. Trans. R. Soc. B, 369(1644), 20130169. https://doi.org/10.1098/rstb.2013.0169

Ferraro, F. R. (2016). No evidence of reaction time slowing in autism spectrum disorder. Autism, 20(1), 116-122. https://doi.org/10.1177/1362361314559986

Fishman, I., Keown, C. L., Lincoln, A. J., Pineda, J. A., \& Müller, R.-A. (2014). Atypical Cross Talk Between Mentalizing and Mirror Neuron Networks in Autism Spectrum Disorder. JAMA Psychiatry, 71(7), 751-760. https://doi.org/10.1001/jamapsychiatry.2014.83

Fogassi, L., Ferrari, P. F., Gesierich, B., Rozzi, S., Chersi, F., \& Rizzolatti, G. (2005). Parietal Lobe: From Action Organization to Intention Understanding. Science, 308(5722), 662667. https://doi.org/10.1126/science.1106138

Fombonne, E. (2009). Epidemiology of Pervasive Developmental Disorders. Pediatric Research, 65(6), 591-598. https://doi.org/10.1203/PDR.0b013e31819e7203

Fonagy, P., Gergely, G., Jurist, E., \& Target, M. (2004). Affektregulierung, Mentalisierung und die Entwicklung des Selbst. Klett-Cotta.

Frith, C. D., \& Frith, U. (2006). The Neural Basis of Mentalizing. Neuron, 50(4), 531-534. https://doi.org/10.1016/j.neuron.2006.05.001

Frith, U., Morton, J., \& Leslie, A. M. (1991). The cognitive basis of a biological disorder: autism. Trends in Neurosciences, 14(10), 433-438. https://doi.org/10.1016/01662236(91)90041-R

Gallese, V., \& Goldman, A. (1998). Mirror neurons and the simulation theory of mind-reading. Trends in Cognitive Sciences, 2(12), 493-501. https://doi.org/10.1016/S13646613(98)01262-5 
Gallese, V., Keysers, C., \& Rizzolatti, G. (2004). A unifying view of the basis of social cognition. Trends in Cognitive Sciences, 8(9), 396-403. https://doi.org/10.1016/j.tics.2004.07.002

Gangopadhyay, N., \& Schilbach, L. (2012). Seeing minds: A neurophilosophical investigation of the role of perception-action coupling in social perception. Social Neuroscience, 7(4), 410-423. https://doi.org/10.1080/17470919.2011.633754

Georgescu, A. L., Kuzmanovic, B., Roth, D., Bente, G., \& Vogeley, K. (2014). The Use of Virtual Characters to Assess and Train Non-Verbal Communication in High-Functioning Autism. Frontiers in Human Neuroscience, 8. https://doi.org/10.3389/fnhum.2014.00807

Gueorguieva, R., \& Krystal, J. H. (2004). Move Over ANOVA: Progress in Analyzing RepeatedMeasures Data andIts Reflection in Papers Published in the Archives of General Psychiatry. Archives of General Psychiatry, 61(3), 310. https://doi.org/10.1001/archpsyc.61.3.310

Häberling, I. S., Corballis, P. M., \& Corballis, M. C. (2016). Language, gesture, and handedness: Evidence for independent lateralized networks. Cortex, 82, 72-85. https://doi.org/10.1016/j.cortex.2016.06.003

Hamilton, A. F. de C. (2008). Emulation and Mimicry for Social Interaction: A Theoretical Approach to Imitation in Autism. Quarterly Journal of Experimental Psychology, 61(1), 101-115. https://doi.org/10.1080/17470210701508798

Hamilton, A. F. de C. (2013). Reflecting on the mirror neuron system in autism: A systematic review of current theories. Developmental Cognitive Neuroscience, 3, 91-105. https://doi.org/10.1016/j.den.2012.09.008

Hamilton, A. F. de C., Brindley, R. M., \& Frith, U. (2007). Imitation and action understanding in autistic spectrum disorders: How valid is the hypothesis of a deficit in the mirror neuron 
system? Neuropsychologia, 45(8), 1859-1868.

https://doi.org/10.1016/j.neuropsychologia.2006.11.022

Happé, F., \& Frith, U. (2006). The Weak Coherence Account: Detail-focused Cognitive Style in Autism Spectrum Disorders. Journal of Autism and Developmental Disorders, 36(1), 525. https://doi.org/10.1007/s10803-005-0039-0

Happé, F. G. E. (1996). Studying Weak Central Coherence at Low Levels: Children with Autism do not Succumb to Visual Illusions. A Research Note. Journal of Child Psychology and Psychiatry, 37(7), 873-877. https://doi.org/10.1111/j.1469-7610.1996.tb01483.x

Happé, F. G. E. (1997). Central coherence and theory of mind in autism: Reading homographs in context. British Journal of Developmental Psychology, 15(1), 1-12. https://doi.org/10.1111/j.2044-835X.1997.tb00721.x

Happé, F., Ronald, A., \& Plomin, R. (2006). Time to give up on a single explanation for autism. Nature Neuroscience, 9(10), 1218-1220. https://doi.org/10.1038/nn1770

Hari, R., Forss, N., Avikainen, S., Kirveskari, E., Salenius, S., \& Rizzolatti, G. (1998). Activation of human primary motor cortex during action observation: A neuromagnetic study. Proceedings of the National Academy of Sciences, 95(25), 15061-15065.

Hasson, U., \& Frith, C. D. (2016). Mirroring and beyond: coupled dynamics as a generalized framework for modelling social interactions. Phil. Trans. R. Soc. B, 371(1693), 20150366. https://doi.org/10.1098/rstb.2015.0366

Hickok, G. (2009). Eight Problems for the Mirror Neuron Theory of Action Understanding in Monkeys and Humans. Journal of Cognitive Neuroscience, 21(7), 1229-1243. https://doi.org/10.1162/jocn.2009.21189 
Hooker, C. I., Verosky, S. C., Germine, L. T., Knight, R. T., \& D’Esposito, M. (2008).

Mentalizing about emotion and its relationship to empathy. Social Cognitive and Affective Neuroscience, 3(3), 204-217. https://doi.org/10.1093/scan/nsn019

Iacoboni, M. (2009). Neurobiology of imitation. Current Opinion in Neurobiology, 19(6), 661665. https://doi.org/10.1016/j.conb.2009.09.008

Iacoboni, M., \& Dapretto, M. (2006). The mirror neuron system and the consequences of its dysfunction. Nature Reviews Neuroscience, 7(12), 942-951. https://doi.org/10.1038/nrn2024

Iacoboni, M., Woods, R. P., Brass, M., Bekkering, H., Mazziotta, J. C., \& Rizzolatti, G. (1999). Cortical Mechanisms of Human Imitation. Science, 286(5449), 2526-2528. https://doi.org/10.1126/science.286.5449.2526

ICD-10-CM, 2018: the complete offical codebook. (2017). CHICAGO: AMER MEDICAL ASSOCIATION.

Idring, S., Rai, D., Dal, H., Dalman, C., Sturm, H., Zander, E., ... Magnusson, C. (2012). Autism Spectrum Disorders in the Stockholm Youth Cohort: Design, Prevalence and Validity. PLOS ONE, 7(7), e41280. https://doi.org/10.1371/journal.pone.0041280

Kaiser, M. D., \& Pelphrey, K. A. (2012). Disrupted action perception in autism: Behavioral evidence, neuroendophenotypes, and diagnostic utility. Developmental Cognitive Neuroscience, 2(1), 25-35. https://doi.org/10.1016/j.dcn.2011.05.005

Kenworthy, L., Black, D. O., Harrison, B., Rosa, A. della, \& Wallace, G. L. (2009). Are Executive Control Functions Related to Autism Symptoms in High-Functioning Children? Child Neuropsychology, 15(5), 425-440.

https://doi.org/10.1080/09297040802646983 
Kliegl. (2010). Experimental effects and individual differences in linear mixed models: estimating the relationship between spatial, object, and attraction effects in visual attention. Frontiers in Psychology. https://doi.org/10.3389/fpsyg.2010.00238

Knapp, M. L., \& Daly, J. A. (2011). The SAGE Handbook of Interpersonal Communication. SAGE Publications.

Kuzmanovic, B., Schilbach, L., Lehnhardt, F.-G., Bente, G., \& Vogeley, K. (2011). A matter of words: Impact of verbal and nonverbal information on impression formation in highfunctioning autism. Research in Autism Spectrum Disorders, 5(1), 604-613. https://doi.org/10.1016/j.rasd.2010.07.005

Lammers, S. (2017, July 15). Production and Perception of Whole-Body Movements to Probe the Social Brain.

Mars, R. B., Neubert, F.-X., Noonan, M. P., Sallet, J., Toni, I., \& Rushworth, M. F. S. (2012). On the relationship between the "default mode network" and the "social brain". Frontiers in Human Neuroscience, 6. https://doi.org/10.3389/fnhum.2012.00189

Marshall, P. J., \& Meltzoff, A. N. (2014a). Neural mirroring mechanisms and imitation in human infants. Phil. Trans. R. Soc. B, 369(1644), 20130620. https://doi.org/10.1098/rstb.2013.0620

Marshall, P. J., \& Meltzoff, A. N. (2014b). Neural mirroring mechanisms and imitation in human infants. Phil. Trans. R. Soc. B, 369(1644), 20130620. https://doi.org/10.1098/rstb.2013.0620

Mehrabian, A. (2017). Nonverbal Communication. Routledge. https://doi.org/10.4324/9781351308724 
Moore, C., Dunham, P. J., \& Dunham, P. (2014). Joint Attention: Its Origins and Role in Development. Psychology Press.

Mukamel, R., Ekstrom, A. D., Kaplan, J., Iacoboni, M., \& Fried, I. (2010). Single-Neuron Responses in Humans during Execution and Observation of Actions. Current Biology, 20(8), 750-756. https://doi.org/10.1016/j.cub.2010.02.045

Oberman, L. M., Hubbard, E. M., McCleery, J. P., Altschuler, E. L., Ramachandran, V. S., \& Pineda, J. A. (2005). EEG evidence for mirror neuron dysfunction in autism spectrum disorders. Cognitive Brain Research, 24(2), 190-198. https://doi.org/10.1016/j.cogbrainres.2005.01.014

Pascolo, P. B., \& Budai, R. (2014). Just how consistent is the mirror neuron system paradigm? Progress in Neuroscience, 29-43. https://doi.org/10.14588/PiN.2013.Pascolo.29

Pennington, B. F., \& Ozonoff, S. (1996). Executive Functions and Developmental Psychopathology. Journal of Child Psychology and Psychiatry, 37(1), 51-87. https://doi.org/10.1111/j.1469-7610.1996.tb01380.x

Persico, A. M., \& Napolioni, V. (2013). Autism genetics. Behavioural Brain Research, 251, 95112. https://doi.org/10.1016/j.bbr.2013.06.012

Pfeifer, J. H., Iacoboni, M., Mazziotta, J. C., \& Dapretto, M. (2008). Mirroring others' emotions relates to empathy and interpersonal competence in children. NeuroImage, 39(4), 20762085. https://doi.org/10.1016/j.neuroimage.2007.10.032

Premack, D., \& Woodruff, G. (1978). Does the chimpanzee have a theory of mind? Behavioral and Brain Sciences, 1(4), 515-526. https://doi.org/10.1017/S0140525X00076512 
Quené, H., \& van den Bergh, H. (2008). Examples of mixed-effects modeling with crossed random effects and with binomial data. Journal of Memory and Language, 59(4), 413425. https://doi.org/10.1016/j.jml.2008.02.002

Ramachandran, V. S., \& Oberman, L. M. (2006). Broken Mirrors: A Theory of Autism. Scientific American, 295(5), 62-69. https://doi.org/10.1038/scientificamerican1106-62

Redcay, E. (2008). The superior temporal sulcus performs a common function for social and speech perception: Implications for the emergence of autism. Neuroscience \& Biobehavioral Reviews, 32(1), 123-142. https://doi.org/10.1016/j.neubiorev.2007.06.004

Rizzolatti, G., \& Arbib, M. A. (1998). Language within our grasp. Trends in Neurosciences, 21(5), 188-194. https://doi.org/10.1016/S0166-2236(98)01260-0

Rizzolatti, G., Fadiga, L., Gallese, V., \& Fogassi, L. (1996). Premotor cortex and the recognition of motor actions. Cognitive Brain Research, 3(2), 131-141. https://doi.org/10.1016/09266410(95)00038-0

Rizzolatti, G., Fogassi, L., \& Gallese, V. (2001). Neurophysiological mechanisms underlying the understanding and imitation of action. Nature Reviews Neuroscience, 2(9), 661-670. https://doi.org/10.1038/35090060

Saxe, R., \& Powell, L. J. (2006). It's the Thought That Counts: Specific Brain Regions for One Component of Theory of Mind. Psychological Science, 17(8), 692-699. https://doi.org/10.1111/j.1467-9280.2006.01768.x

Schultz, R. T. (2005). Developmental deficits in social perception in autism: the role of the amygdala and fusiform face area. International Journal of Developmental Neuroscience, 23(2-3), 125-141. https://doi.org/10.1016/j.ijdevneu.2004.12.012 
Segrin, C. (2000). Social skills deficits associated with depression. Clinical Psychology Review, 20(3), 379-403. https://doi.org/10.1016/S0272-7358(98)00104-4

South, M., Ozonoff, S., \& Mcmahon, W. M. (2007). The relationship between executive functioning, central coherence, and repetitive behaviors in the high-functioning autism spectrum. Autism, 11(5), 437-451. https://doi.org/10.1177/1362361307079606

Spengler, S., Bird, G., \& Brass, M. (2010). Hyperimitation of Actions Is Related to Reduced Understanding of Others' Minds in Autism Spectrum Conditions. Biological Psychiatry, 68(12), 1148-1155. https://doi.org/10.1016/j.biopsych.2010.09.017

Sperduti, M., Guionnet, S., Fossati, P., \& Nadel, J. (2014). Mirror Neuron System and Mentalizing System connect during online social interaction. Cognitive Processing, 15(3), 307-316. https://doi.org/10.1007/s10339-014-0600-x

Thioux, M., Gazzola, V., \& Keysers, C. (2008). Action Understanding: How, What and Why. Current Biology, 18(10), R431-R434. https://doi.org/10.1016/j.cub.2008.03.018

Timmermans, B., \& Schilbach, L. (2014). Investigating Alterations of Social Interaction in Psychiatric Disorders with Dual Interactive Eye Tracking and Virtual Faces. Frontiers in Human Neuroscience, 8. https://doi.org/10.3389/fnhum.2014.00758

Tomasello, M., Carpenter, M., Call, J., Behne, T., \& Moll, H. (2005). Understanding and sharing intentions: the origins of cultural cognition. The Behavioral and Brain Sciences, 28(5), 675-691; discussion 691-735. https://doi.org/10.1017/S0140525X05000129

Van Overwalle, F., \& Baetens, K. (2009). Understanding others' actions and goals by mirror and mentalizing systems: A meta-analysis. NeuroImage, 48(3), 564-584. https://doi.org/10.1016/j.neuroimage.2009.06.009 
Vogeley, K. (2017). Two social brains: neural mechanisms of intersubjectivity. Phil. Trans. R. Soc. B, 372(1727), 20160245. https://doi.org/10.1098/rstb.2016.0245

Vogeley, K., \& Bente, G. (2010). “Artificial humans”: Psychology and neuroscience perspectives on embodiment and nonverbal communication. Neural Networks, 23(8), 1077-1090. https://doi.org/10.1016/j.neunet.2010.06.003

White, S. J., Frith, U., Rellecke, J., Al-Noor, Z., \& Gilbert, S. J. (2014). Autistic adolescents show atypical activation of the brain's mentalizing system even without a prior history of mentalizing problems. Neuropsychologia, 56, 17-25. https://doi.org/10.1016/j.neuropsychologia.2013.12.013

Williams, J. H. G., Whiten, A., Suddendorf, T., \& Perrett, D. I. (2001). Imitation, mirror neurons and autism. Neuroscience \& Biobehavioral Reviews, 25(4), 287-295. https://doi.org/10.1016/S0149-7634(01)00014-8

Wollschläger, D. (2015). Grundlagen der Datenanalyse mit R: Eine anwendungsorientierte Einführung. Springer-Verlag.

World Medical Association. (2013). World Medical Association Declaration of Helsinki: ethical principles for medical research involving human subjects. JAMA, 310(20), 2191-2194. https://doi.org/10.1001/jama.2013.281053 


\section{Declaration of Authorship}

I am aware of and understand the University's policy on plagiarism and I certify that this thesis is my own work, except where indicated by referencing, and that I have followed good academic practices.

Signed,

Milena Marx, August 2018

\section{Conflict of Interest}

The author has no conflict of interest to declare. 